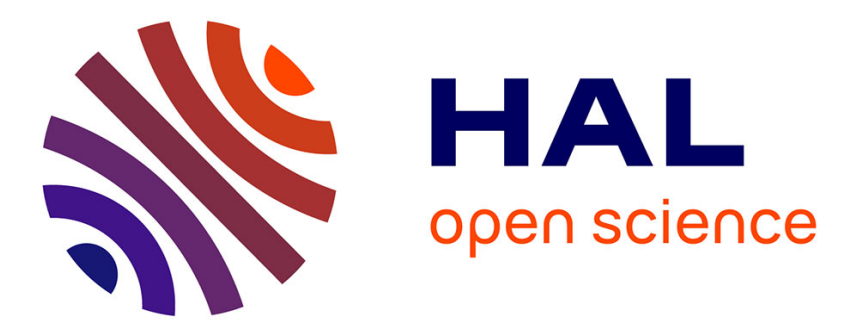

\title{
Cranial anatomy of Pholidosaurus purbeckensis from the Lower Cretaceous of France and its bearing on pholidosaurid affinities
}

\author{
Jérémy Martin, Julien Raslan-Loubatié, Jean-Michel Mazin
}

\section{To cite this version:}

Jérémy Martin, Julien Raslan-Loubatié, Jean-Michel Mazin. Cranial anatomy of Pholidosaurus purbeckensis from the Lower Cretaceous of France and its bearing on pholidosaurid affinities. Cretaceous Research, 2016, 66, pp.43-59. 10.1016/j.cretres.2016.05.008 . hal-01625346

\author{
HAL Id: hal-01625346 \\ https://hal.science/hal-01625346
}

Submitted on 27 Oct 2017

HAL is a multi-disciplinary open access archive for the deposit and dissemination of scientific research documents, whether they are published or not. The documents may come from teaching and research institutions in France or abroad, or from public or private research centers.
L'archive ouverte pluridisciplinaire HAL, est destinée au dépôt et à la diffusion de documents scientifiques de niveau recherche, publiés ou non, émanant des établissements d'enseignement et de recherche français ou étrangers, des laboratoires publics ou privés. 
Cranial anatomy of Pholidosaurus purbeckensis from the Lower

Cretaceous of France and its bearing on pholidosaurid affinities

Jeremy E. Martin ${ }^{\mathrm{a},{ }^{,}}$, Julien Raslan-Loubatie ${ }^{\mathrm{a}, \uparrow}$, Jean-Michel Mazin ${ }^{\mathrm{a}, \mathrm{b}}$

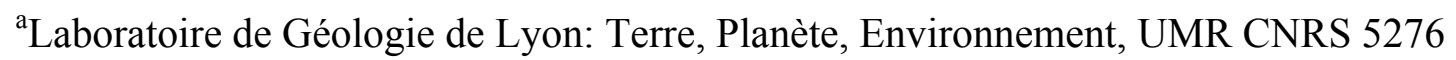

(CNRS, ENS, Université Lyon1), Ecole Normale Supérieure de Lyon, 69364 Lyon

cedex 07, France, jeremy.martin@ens-lyon.fr

${ }^{\mathrm{b}}$ La Plage aux pterosaurs, Le Mas de Pégourdy, 46150 Crayssac,

jm.mazin@plageauxpterosaures.com

Footnote: ${ }^{\dagger}$ Deceased

*Corresponding author 


\begin{abstract}
New and nearly complete cranial remains of Pholidosaurus purbeckensis are described on the basis of specimens recovered from the Berriasian locality of Cherves-de-Cognac, France. Two skulls, associated mandibles and a set of dorsal osteoderms are available and allow a refinement of the anatomy of the genus, known otherwise from coeval deposits in Germany and England. Because of its longirostrine morphology, convergent with other crocodylomorph lineages, the phylogenetic relationships of Pholidosaurus are likely to be affected by Long Branch Attraction problems. Various tests of removing/excluding longirostrine lineages confirm that Dyrosauridae have a labile position and that their affinities with Pholidosauridae are weakly supported. Results from comparative anatomy and phylogenetic analyses recover Pholidosaurus as the basalmost member of Pholidosauridae, a group closely related to Goniopholididae. Pholidosaurus is recovered together with abundant remains of Goniopholis and with more limited remains of Theriosuchus. The paleoecology of Pholidosaurus and more generally, of Pholidosauridae, is discussed.
\end{abstract}

Key words: Pholidosauridae, Europe, Neosuchia, Cretaceous, longirostry

\title{
1. Introduction
}

The genus Pholidosaurus was erected in the middle of the XIX ${ }^{\text {th }}$ century with $P$. schaumburgensis von Meyer, 1841 for specimens found in the Obernkirchen Sandstone (Lower Cretaceous) of north-western Germany (von Meyer, 1841, 1846). A number of longirostrine forms were eventually erected from the Purbeck Limestone Group of England (Owen, 1878; Mansel-Pleydell, 1888; Watson, 1911; Andrews, 1913). Taxonomic revisions of these taxa by Salisbury et al. (1999) and Salisbury 
(2002) concluded that our current understanding of the genus Pholidosaurus includes two species: $P$. schaumburgensis Meyer, 1841 from Germany and $P$. purbeckensis (Mansel-Pleydell, 1888) from England. Salisbury et al. (1999) suggested that $P$. purbeckensis could be a synonym of $P$. schaumburgensis. Pending a revision of German specimens, it remains plausible that the genus Pholidosaurus might contain a single species only. Although quite a few specimens are referred to Pholidosaurus, the best-preserved and most complete one is NHMUK 3956, a disarticulated skeleton preserved on a slab from the Purbeck Limestone Group of Swanage, UK originally described by Andrews (1913). Although this specimen is fairly complete, bones are only visible from one side and many anatomical details of the cranial elements are either not preserved or not visible.

Improving our understanding of Pholidosaurus osteology is timely in the context of recent phylogenetic investigations of neosuchian relationships, especially concerning the resolution over the affinities of longirostrine lineages with other crocodylomorphs. Although originally viewed as closely related to Goniopholididae (Buffetaut, 1982), subsequent phylogenetic works have often grouped Pholidosauridae with Thalattosuchia and Dyrosauridae, altogether in a derived position within Neosuchia (e.g. Buckley and Brochu, 1999; Wu, Russell, and Cumbaa, 2001; Sereno et al., 2001; Jouve et al., 2006; Pol and Gasparini, 2009). Recent work (Martin and Buffetaut, 2012; Martin et al., 2014) proposed a different hypothesis, grouping Pholidosauridae and Goniopholididae in the clade Coelognathosuchia. Also, the recent phylogenetic hypothesis over the placement of Thalattosuchia at the base of Crocodylomorpha (Wilberg, 2015b,a) reconciles early views (Buffetaut, 1982; Benton and Clark, 1988), with the consequence of leaving only two longirostrine lineages, Dyrosauridae and Pholidosauridae in a derived 
neosuchian position. This highlights the previous unnatural grouping of Thalattosuchia with these longirostrine forms and questions whether the remaining grouping of Pholidosauridae with Dyrosauridae can be supported. Moreover, the phylogenetic position of Pholidosaurus and of Pholidosauridae can have consequences for our understanding of the relationships of the neosuchian-eusuchian transition. As such, recent studies recovered the genera Susisuchus and Isisfordia; originally considered as the most basal eusuchians (Salisbury et al., 2003, 2006), to be distantly related to Eusuchia and sitting in a basal position relative to Goniopholididae (Turner and Pritchard, 2015; Turner, 2015). In this context, a Pholidosauridae + Goniopholididae grouping would challenge the position of Susisuchidae and ultimately, the content of Eusuchia.

The present work is in continuity with a master thesis (Raslan-Loubatié, 2007) and aims at providing a comprehensive anatomical description of two recently recovered specimens attributable to the genus Pholidosaurus from the Berriasian of Cherves-de-Cognac, Charente, France (Fig. 1). This represents the first discovery of relatively complete remains of Pholidosaurus from France, filling a biogeographic gap but also enhancing our knowledge on the anatomy of the genus by describing features not visible or not preserved in specimens reported so far. The specimens are represented by the most completely known skulls and mandibular remains of Pholidosaurus to date.

Institutional abbreviations - IMGPGö, Institut und Museum für Geologie und Paläontologie der Georg-August-Universität, Göttingen, Germany; CHV and TL, Collection Cherves-de-Cognac, Musée d'Angoulême, Charente, France; NHMUK, Natural History Museum, London, United Kingdom. 


\section{Geological setting}

The site of Cherves-de-Cognac (Berriasian, Charente, France) is located in the quarry of Champblanc, in the vicinity of the town of Cognac (Fig. 1). It is a huge open quarry of gypsum, which exposes a $40 \mathrm{~m}$ section made of an alternation of 81 levels of clay, marl and limestone, overlapping or intercalated with several banks of gypsum. Formerly considered as upper Jurassic in age (Purbeckian) (Coquand 1858, 1860; Buffetaut et al. 1989; Hervat and Hervat 1993; Le Loeuff et al. 1996), a recent dating reassessment from ostracods, charophytes and dinoflagellates leads to propose an early to middle Berriasian age to this site, making the section of Champblanc an equivalent of the lower part of the Middle English Purbeck Limestone Group (Colin et al. 2004; El Albani et al. 2004). A sedimentological approach of the section of Champblanc leads to recognize a progression from a hypersaline lagoon at the bottom of the section to continental fresh water lacustrine environments in the uppermost levels (El Albani et al. 2004; Mazin et al. 2008; Pouech 2008), which is in accordance with the paroxysm of the general regressive context in Western Europe during the latest Jurassic and the earliest Cretaceous.

This site is characterized by its rich vertebrate fauna, with 63 of the 81 successive levels of the Champblanc section being fossiliferous with macro-remains (1763 specimens excavated from a complex of 5 marly levels) and micro-remains (40,594 isolated teeth collected by screen-washing of a total of 12 tons of sediment). All the main vertebrate clades are represented: Chondrichthyes (2 families), Osteichthyes (5 families), Amphibia (1 family), Lepidosauromorpha (2 families), Testudines (2 families), Crocodylomorpha (4 families), Dinosauria including Aves (10 families), Pterosauria (1 family), and Mammals (6 families), that is to say 33 
identified families (Mazin et al. 2006, 2008; Pouech 2008). The specimens of Pholidosaurus described in this work all come from a single horizon called C36 (Pouech et al. 2008).

On a taphonomical point of view, the specimens are well preserved without trace of transportation, even though skulls are often flattened due to the sediment compaction. The numerous isolated teeth collected by screen-washing are perfectly preserved with rare abrasion or break marks. The fossil assemblage has been shortly transported from the proximal emerged land towards the area of deposition, probably in deltaic conditions, which reveals a continental taphocenosis concentrated in a littoral depositional environment (Pouech 2008).

Among this vertebrate assemblage, crocodilians are common with four families identified: Atoposauridae, Bernissartidae, Pholidosauridae and Goniopholidae, from macro-remains as well as from micro-remains (Billon-Bruyat, 2003; Raslan-Loubatié, 2007; Mazin et al. 2006a, 2008; Pouech, 2008). Macroremain crocodilian assemblage is strongly dominated by the goniopholids, which represents more than $50 \%$ of excavated vertebrate specimens. Pholidosaurids are less common.

\section{Systematic paleontology}

Mesoeucrocodylia Whetstone and Whybrow, 1983

Coelognathosuchia Martin, Lauprasert, Buffetaut, Liard and Suteethorn, 2014

Pholidosauridae Zittel and Eastman, 1902

Pholidosaurus von Meyer, 1841

Pholidosaurus purbeckensis (Mansel-Pleydell, 1888) (see Figs 2-8) 
Holotype. DORCM G97, a cranium from the Purbeck Limestone Group of the Isle of Purbeck or from Swanage (see Salisbury, 2002).

Referred Material. CHV03.100: Musée d'Angoulême, complete skull with mandibles and osteoderms; TL 100: Thierry Lenglet Collection, housed in Musée d'Angoulême: deformed skull with right mandible;

Revised Diagnosis. Longirostrine neosuchian with the following combination of characters, some of which are shared with other pholidosaurids $\left(^{*}\right)$ or goniopholidids (**): elongated rostrum, representing $\sim 70 \%$ of total skull length $(*)$; wide and planar interorbital space; semicircular arrangement of the premaxillary tooth row $(* *)$; anterior processes of maxillae dividing the premaxillae in ventral view $(* *)$; long and slender nasals, excluded from posterior narial margin but reaching the posterior tip of premaxillae $(*)$; wide depression located on the posteriormost region of the maxilla, almost touching the jugal $(* *)$; quadrangular supratemporal fenestrae over a planar skull table $(*, * *)$; jugal contributing to lateral margin of suborbital fenestra; convex outline of the ectopterygoid at margin of suborbital fenestra (*); enlarged and confluent third and fourth dentary alveoli $(* *)$; long mandibular symphysis extending to the level of the $21^{\text {st }}$ mandibular alveolus; presence of a small external mandibular fenestra; premaxilla with 5 alveoli; maxilla with 22-23 alveoli; dentary with 27-28 alveoli.

Locality and Horizon: Cherves-de-Cognac, Carrière de Champblanc, horizon C36, lower to middle Berriasian.

Note. The most recent taxonomic revision (Salisbury, 2002) concluded that Pholidosaurus purbeckensis had priority over Pholidosaurus decipiens. Because the holotype of $P$. schaumburgensis consists of a natural mould and therefore does not ease comparisons with the material described here, the Cherves-de-Cognac specimens 
are provisionally referred to $P$. purbeckensis. Further studies will have to elucidate whether $P$. purbeckensis is a junior synonym of $P$. schaumburgensis but this is out of the scope of the present paper.

\section{Description}

General shape and preservation. Table 1 provides measurements for the bestpreserved specimen, CHV03.100, which underwent some dorsoventral compaction. For this reason, most features of the braincase are not readily accessed. Despite the presence of small fractures, most of the general shape has been retained and such fragile structures such as the pterygoid wings have not much suffered from compaction. The rostrum, with its laterally expanded premaxilla, is about twice as long as the postorbital region. The skull table is nearly quadrangular with undulating lateral edges. The anterolateral corners of the skull table have a projecting process and the posterolateral corners have developed squamosal lobes. The interorbital space is wide and the orbits are slightly smaller than the supratemporal fenestrae. In ventral view, the tooth row does not penetrate far posteriorly between the suborbital fenestrae. These fenestrae are marked anteriorly and posteriorly by a notch and attain their maximum width at mid-way. The gracile mandibular rami associated with CHV03.100 have been deformed, especially the left element, which appears to be straight. The right element retains its original curvature. To the exception of the surangular-dentary junction restored with plaster on the right ramus, the mandibles are complete and a small external mandibular fenestra is visible on the left ramus. TL 100 consists of a complete skull associated with a right mandibular ramus. The skull underwent heavy distortion, being slightly dorsoventrally flattened and twisted along its anteroposterior axis. The right temporal area and most of the palate is missing, to 
the exception of a portion of the left pterygoid wing and ectopterygoid. Except when TL is explicitly mentioned, the description directly refers to CHV03.100.

Ornamentation. The skull table is ornamented with small, evenly spaced circular pits, which uniformly cover the dorsal surface of the parietal, squamosal, postorbital, frontal and interorbital area. This pattern is also observed on the dorsal surface of the quadratojugal and jugal, which contrasts with the smooth surface of the quadrate. The circular pits gradually become elongated in the antorbital area; the entire surface of the rostrum shows a pattern of densely packed furrows. A similar observation is made on the posterolateral and ventral surfaces of the mandible, which are covered with small circular pits. Furrows cover the lateral surface of the dentary for its entire length.

\subsection{Skull}

Premaxilla. CHV03.100 has the best-preserved premaxillae (Figs. 2, 3, 5), being slightly damaged anteriorly. In dorsal view, the premaxillae are wider than the maxillary rostrum and are separated from it by a long and marked notch. The external nares are large covering nearly half of the surface of the premaxillae. The left premaxillary alveolar row is complete and totalizes five alveoli. This count is confirmed on the right row of TL 100. A large diastema is located between the first (small) and the second alveoli. The second and third alveoli are coalescent and the fourth is closely placed to them. A fifth alveolus is small and opens just posterior to the fourth. A two centimeters diastema separates the last premaxillary alveolus from the first maxillary alveolus. No incisive foramen could be detected. As seen in both CHV03.100 and TL 100, backward from the level of the second alveolus, the 
premaxillae do not meet medially. Here, the pointed anterior tip of the maxillae divides the premaxillae.

Maxilla. The maxilla (Figs. 2, 3, 4) is a rectilinear bone for its entire length. It has extensive contacts with the premaxilla and nasal. As seen on both sides of CHV03.100 and on the right side of TL 100, posteriorly, the maxilla contacts the lacrimal and the anterior tip of the jugal at the level of the maxillary depression (see description in Martin and Buffetaut, 2012). In ventral view, the maxillae send an anterior projection between the premaxillae, reaching the level of the second alveolus. The maxillae meet along their midline for most of their length, to the exception of the posterior area, which is divided by the anterior processes of the palatines. The posteriormost branches of the maxillae participate in the anterolateral margin of the suborbital fenestrae and contact the jugal at this level. On both sides of the skull, the maxilla does not contact the ectopterygoid (as also seen in NHMUK R. 36721, JEM pers. obs.). As seen in both specimens, the maxillary alveolar borders protrude as distinct collar, a condition previously described in NHMUK R.3956 (Andrews, 1913). The maxillary tooth row can be described as homodont (Table $\mathrm{X}$ for measurements). The left maxillary tooth row of CHV03.100 hosts twenty-two or twenty-three alveoli. The right tooth row possesses twenty-two alveoli, but the posteriormost contact with the jugal is crushed and the total count could be twentythree. Alveoli are separated from the following ones by a distance equivalent to the diameter of one alveolus. In some instances, this is not the case and couplets (i.e. closely spaced but not coalescing alveoli) are identified on the left side of the maxilla for alveoli 3-4, 8-9, 11-12. Posterior to the sixteenth alveolus, all alveoli are smaller and close to each other. On the right side, couplets are seen on alveoli 6-7, 8-9, 11-12, 
and behind the seventeenth alveolus all alveoli are small and close to each other. Occlusal pits are identified just posterior to the right fourteenth alveolus, within the left 11-12 couplet, and posterior to the left thirteenth. Only marked on the right posterior side, small perfectly circular occlusal pits are present close to the anterior and posterior margins of the $18^{\text {th }}$ alveolus, then they are interfingering between the $19^{\text {th }}$ and $20^{\text {th }}$ alveoli (Fig. 3 ).

Nasal. The nasal (Figs. 2,4) is a thin bone that extends anteriorly. The nasal contacts the thin posterior process of the premaxilla near the level of the fifth maxillary alveolus. In the posterior region, the nasal is wider and contacts both the prefrontal and lacrimal. Both nasals are sutured along their medial, to the exception of their posterior end, which is divided by the anterior frontal process.

Prefrontal. The prefrontal (Fig. 2) contributes to the medial margin of the orbit. It curves in an anteromedial direction and is delimited by the frontal and lacrimal. Its anterior process contacts the nasal and reaches slightly further anteriorly than the frontal. In ventral view, the left prefrontal pillar is visible. Its anterior margin is convex and it is mediolaterally compressed. The prefrontal pillar contacts the palate.

Lacrimal. The tear-drop shaped lacrimal (Fig. 2) contributes to the anterior margin of the orbit. Its lateral margin contacts the jugal and extensively the maxilla, just above the maxillary depression. Its medial margin contacts the prefrontal and the nasal. The lacrimal reaches further anteriorly than the prefrontal. 
Postorbital. The postorbital makes the anterolateral corner of the skull table. Its anterior margin is not straight and overhangs the dorsal margin of the orbit by sending a convex cap (Fig. 5). The postorbital-squamosal suture is located near the anterior half of the skull table. In lateral view, the postorbital is almost entirely excluded from the lower temporal fenestra by an anterior projection of the squamosal that attains the postorbital bar (Fig. 6).

The postorbital bar is best preserved on the left side of CHV03.100 (Fig. 5). It consists of a massive pillar that nearly, but not completely closes the posterior margin of the orbits. The postorbital sends a mediolaterally compressed process on the anterolateral corner of the postorbital bar. For half of the height of the postorbital bar, the anterolateral surface is ornamented with pits and bulges, which overhang the lateral smooth surface of the postorbital. The most ventral tip of this process is smooth and although it is broken off, as currently preserved it closely approaches the dorsal surface of the jugal. The transverse suture between the postorbital and the ascending jugal is visible on the lateral margin of the postorbital bar. In lateral view, the anterior edge of the postorbital bar is oblique. The jugal contribution to the postorbital bar is not inset as it arises in line from the lateral ornamented surface of the jugal. At the base of this bar, on the anteroventral corner of the lower temporal fenestra, a foramen is visible. Dorsally to it, the squamosal sends a ventral lamina that touches the postorbital bar.

Frontal. The frontal (Fig. 2) has a flat surface and is a wide bone that makes the anterior part of the skull table. Its participation into the orbital margin is small, located at the posteromedial corner of the orbit. The frontoparietal suture penetrates between the supratemporal fenestrae. The frontal contributes to the anteromedial 
margin of the supratemporal fenestra. Its surface is slightly concave, making a modest smooth shelf in the anteromedial corner of the fossa.

Parietal. The parietal (Fig. 2) makes a flat shelf between the supratemporal fenestrae together with the participating frontal. The parietal also contributes to the posteromedial margins of the supratemporal fenestrae. The parietal does not overhang the fenestrae and at this level, the medial wall that borders the braincase is not vertical but is visible from a dorsal view. The dorsal surface of the parietal is flat, to the exception of its concave posteromedian margin close to the edge of the skull table, which seems to accommodate the dorsal process of the supraoccipital. In dorsal view, the contour of the posterior margin that sits above the supraoccipital makes a wide $\mathrm{W}$, a condition also observed in Goniopholis.

Squamosal. The squamosal (Fig. 2) is a long bone that extends on most of the lateral margin of the skull table, the anterior end consisting of the postorbital. The squamosal also contributes substantially to the posterolateral margin of the supratemporal fenestrae. In dorsal view, the lateral margin of this bone is undulated with a constriction behind the level of the supratemporal fenestrae. Posterolaterally away from the skull table, the squamosals possess wide lobes that are not ornamented at their tip. In posterior view, the squamosal makes the uppermost portion of the paroccipital process. Medial to this, the squamosal consists of an extension of the ornamented skull table, which overhangs the exoccipital. In lateral view, the squamosal does not contact the quadrate as it is separated from it by the exoccipital and by the cranioquadrate groove. The squamosal reaches far anteriorly contributing 
to the dorsal wall of the lower temporal fenestra and touching the posterior margin of the postorbital bar.

Supraoccipital. Although sutures are difficult to observe, the supraoccipital seems to contribute to the skull table in the midline concavity of the parietal (Fig. 2). In posterior view (Fig. 6), the supraoccipital possesses a median pillar that penetrates ventrally between the adjoining exoccipitals. At this level, the dorsal surface of the supraoccipital gives a concave outline to the skull table, as seen from a dorsal view. More laterally, on each side, the supraoccipital presents two robust posterior spines that stand out just below the parietal. The left spine is broken off.

Jugal. The jugal makes the ventrolateral margin of the orbit and most of the temporal bar of the lower temporal fenestra (Figs. 2, 3, 4). The lower temporal bar is transversely flattened. The jugal, through its contact with the maxilla participates in the posteriormost margin of the maxillary depression. In ventral view, the maxilla and ectopterygoid do not meet, thus allowing for a jugal contribution to the lateral margin of the suborbital fenestra. This unusual feature is observed in both CHV03.100 and TL 100.

Quadratojugal. The quadratojugal makes the posterior margin of the temporal arcade, where it participates in the posterior lower corner of the lower temporal fenestra fenestra, and in about a third of the length of the lower temporal bar (Figs. 2, 3, 4). Here, it sends an acute process along the dorsal edge the bar. The quadratojugal is not reaching the posterior end of the quadrate and therefore the quadrate is visible in lateral view. The remnant of a quadratojugal spine is visible on the right side of 
CHV03.100, but the anterior tip is broken off. The spine emerges at midway along the posterior margin of the lower temporal fenestra. The quadratojugal does not reach the postorbital bar. As seen in ventral view, the quadratojugal sends an anterior process below the squamosal.

Quadrate. The right quadrate of CHV03.100 has the best-preserved condyle (Fig. 6). The lateral hemicondyle occupies about two-third of the width of the whole condyle. It is dorsoventrally flattened and slightly convex. The medial hemicondyle is separated from the lateral one by a narrow vertical embayment, which aligned on the dorsal surface of the quadrate with a ridge that delimits the lateral margin of the cranioquadrate passage. The medial hemicondyle protrudes posteriorly and has the shape of a vertical pulley. In ventral view (Fig. 3), the quadrate shows a bifurcated acute scar, which corresponds to the crest A of Iordansky (1973). This crest is located at midway from the posterior edge and from the anterior limit with the lower temporal fenestra. Its posterior end eventually bifurcates in two crests anteriorly but palatal bones obscure further relationships with the braincase. Crest A of Iordansky (1973) is visible on the posterior edge of the quadrate ramus, where the quadrate is overlapped by a thin lamina of the exoccipital.

Exoccipital. The exoccipital is visible in posterior view although as a result of dorsoventral compression, its paroccipital process is also largely facing dorsally (Figs. $2,6)$. The dorsomedial corner of the exoccipital is vertical and ascends to contact the level of the parietal-squamosal suture, which overhangs the occipital surface of the skull. Medially, the exoccipitals meet above the foramen magnum. The lateral edges of the paroccipital process are robust and bear striae serving as muscular anchors. 
Here, the exoccipital supports the squamosal that contributes to this muscle attachment. Lateroventrally, the paroccipital process overhangs the laterally opened cranioquadrate passage. This passage is delimited ventrally by a thin lamina of the exoccipital that wraps the medial margin of the quadrate branch. Above this quadrate branch, the exoccipital consists of a strong ventral projection serving as a muscular attachment. More medially, at the end of this muscular attachment, the exoccipital is pierced by the perfectly circular foramen XII, which is in line with the foramen magnum. The foramen vagus is located in a lateroventral position relative to the foramen XII and consists of a single opening. On the right side, at the medial edge with the quadrate and basioccipital, a pair of slit-like foramina could correspond to the foramina caroticum posterius. The exoccipital builds the pillars on the dorsolateral corner of the occipital condyle.

Basioccipital and Basisphenoid. The basioccipital is visible in posterior view, and builds the occipital condyle (Fig. 6). A descending process of the exoccipital overlaps its lateral surface. Ventrally, the basioccipital possesses a pair of lobes presenting on their ventral surfaces prominent muscle scars. Although the basioccipital plate fully faces posteriorly, it is not developed vertically but is split in two lateral regions, which are somehow projecting posteriorly due to the development of the lobes. Medially, the ventral margin of the basioccipital plate is notched, showing an ascending process of the basisphenoid in posterior view. Further information on the median Eustachian foramen or the suture of the basisphenoid with the pterygoid is obscured by preservation. Nevertheless, in ventral view, the basisphenoid shows a short contribution, which is delimited anteriorly by the pterygoid plate. 
Laterosphenoid. The complete left laterosphenoid as well as the anterolateral tip of the right laterosphenoid are visible in ventral view (Fig. 3). The capitate process is triangular, and is expanded laterally. The tip of the capitate process does not touch the postorbital bar. A thin muscular crest runs along the entire ventral surface of the bone. The laterosphenoid supports the frontal and parietal at the base of the anteromedial corner of the supratemporal fenestra.

Pterygoid. The pterygoid makes the posteromedial and posterior end of the suborbital fenestra, where it is notched (Fig. 3). The pterygoid also makes the posterior and about two-third of the lateral margin of the choanae. Here, the pterygoid sends two anterior processes along the lateral edges of the palatine, participating for about two centimeters in the palatine bar. The pterygoid wings have an unusual outline with an extensive posterolateral margin oriented anterolaterally: the posterolateral edge of the pterygoid wing is located anteriorly to the posteromedial edge (Fig. 3). The torus transiliens makes the whole lateral margin of the pterygoid wing. The posteroventral margin of this torus is slightly upturned and numerous vascularized foramina are observed in lateral view. The posteromedial zone of the adjoining pterygoids consists of a wide concave area that follows the outline of the bilobate basioccipital plate. The pterygoid participates in the posterior corner of the suborbital fenestra. A septum is present but its extent is difficult to establish.

The choanae are longer than wide and open across the pterygoids and palatines. The lateral wall of the choanae is primarily made of the pterygoid, which is juxtaposed on the palatine. A median septum runs at least for the anterior length of the choanal aperture. 
Ectopterygoid. As seen in ventral view (Fig. 3), the ectopterygoid makes the posterolateral margin of the suborbital fenestra, where it is convex. The dorsal process of the ectopterygoid exclusively sutures to the jugal as seen in both specimens. There is no contact between the ectopterygoid and the posterior process of the maxilla. The posterior process of the ectopterygoid does not reach the posterior margin of the pterygoid wing, leaving more than one centimeter of the pterygoid visible in ventral view, as seen on both specimens.

Palatine. The palatines retain parallel edges throughout their length (Fig. 3). To the exception of the posteriormost interfenestral region made by the pterygoids, the palatines build the medial margin of the suborbital fenestrae. The palatines barely expand on the anterior margin, which consists of the maxillae. On the palate, the anterior process of the palatines wedges between the maxillae at the level of the sixteenth maxillary alveolus. This process of the palatines is about as wide as the rest of the palatines and is U-shaped. The palatines make the anterior margin of the choanae.

\subsection{Mandible}

External mandibular fenestra. Only visible on the nicely preserved left ramus of CHV03.100 is a small, slit-like, longer than high external mandibular fenestra. It is located in the higher third of the mandible and in the anterior part of the surangular. Its ventral border is exclusively made by the angular. The dentary participates in the anterodorsal corner by sending a triangular projection. Most of its dorsal margin is made by the surangular. 
Dentary. The dentary is expanded laterally in its anterior region at the level of the largest dentary alveoli (Fig. 7). To this exception, most of the dentary consists of a slender and straight bone for the entire mandibular symphysis length. In CHV03.100, the left dentary hosts twenty-seven alveoli and the right dentary hosts twenty-eight alveoli. The right dentary of TL 100 has a complete row, which hosts twenty-seven alveoli. The symphysis is extensive and ends posteriorly between the level of the nineteenth and twentieth dentary alveoli. To the exception of the anteriormost region of the tooth row, the rest of it is straight in lateral view. The first alveolus projects anterodorsally and is separated from the second alveolus by a diastema, which together with all remaining alveoli does project dorsolaterally. The third and fourth alveoli are confluent and raised above the tooth row (Fig. 7C, D). Alveolar couplets are observed on the left ramus of CHV03.100 for alveoli 8-9 and 12-13; and on the right ramus for alveoli 9-10, 14-15 and 16-17. Occlusal pits are identified on the left ramus between the $20^{\text {th }}$ and $21^{\text {st }}$, between the $21^{\text {st }}$ and $22^{\text {nd }}$.

Splenial. The splenial participates in the mandibular symphysis as a triangular process (Fig. 7). In dorsal view, its anterior process wedges between the dentaries at the level of the fourteenth alveolus. In ventral view, its anterior process is thin and ends at the level of the fifteenth alveolus. From the twenty-first alveolus until the end of the tooth row, the splenial contributes to the medial alveolar wall. In ventral view, the left ramus shows the posterior tip of the splenial contacting the anterior tip of the angular. On the relatively well-preserved left ramus of CHV03.100, the medial surface of the splenial can be followed until its posterior end, which makes the anterior margin of the medial mandibular fossa. Here, the splenial is very thin and many fractures run over its surface rendering difficult the identification of the coronoid. 
Angular. The angular builds the posterior and ventral region of the mandible (Fig. 7). In lateral view and ahead of the external mandibular fenestra, the angular sends an extensive pointed process between the dentary and splenial. This process terminates at the level of the twenty-sixth or twenty-seventh dentary alveoli. The angular sends a long posterodorsal process that reaches the level of the retroarticular process and prevents the surangular from reaching the posteriormost tip of the mandible. In ventral view, the posterior margin of the angular consists of a thin bone. Here, the anchor area for Musculus pterygoideus posterior is restricted to the medial margin of the angular.

Surangular. The surangular makes the posterodorsal region of the mandible (Fig. 7). In lateral view, its profile view is gently convex. At the level of the articular capsule, the surangular has a dorsally expanded lamina that nearly hides the articular in lateral view. The attachment for Musculus adductor mandibulae externus superficialis and medialis on the dorsal surface of the surangular is long with a relatively constant width. This muscle insertion area is wider in the anterior part and presents a fine pattern of rugosity terminating with a hook at its anteriormost end (Fig. 7E, F). In its anterior part, the surangular send a forked process that wedges between the dentary (laterally) and the splenial (medially) and eventually touches the posterior margin of the twenty-seventh alveolus. The lateral surangular process is shorter than the medial (dorsal) process.

Articular. The articular makes the posteromedial region of the mandible (Fig. 7). Its retroarticular process is longer than wide. The retroarticular process consists of a thin 
lamina with a convex median margin in dorsal view. At its posterior tip, the right retroarticular process possesses a distinct hook, which is also identified as partly eroded on the left element. On the medial edge, the transition with the articular capsule corresponds to an anteroventrally directed trough. In medial view and below the retroarticular process, the surface of the articular is deeply concave. The lateral hemicondylar facet is anteriorly expanded whereas the medial hemicondylar facet is anterodorsally directed. These articular facets are divided by a shallow oblique crest. The foot of the articular sends a blunt process that does not reach the ventralmost level of the medial mandibular fossa. The articular foot is not sutured to the medial wall of the surangular but both structures are separated from each other by a deep fossa. The foramen aëreum could not be identified.

\subsection{Dentition}

To the exception of size variation in the premaxilla and anterior region of the dentary, the dentition is homodont. The tooth crown consists of a slender cone affected by a medial bent at mid-height (Fig. 8). The enamel surface is ornamented with obvious apicobasal ridges, about eight on each labial and mesial surfaces. These ridges are individualized at the base of the crown and converge near the apex. The mesiodistal carinae are present and difficult to discern from the ridges, which are identical in development.

\subsection{Postcranium}

Proatlas. The proatlas is preserved compressed over the dorsal surface of the right

third osteoderm (Fig. 9). It shows its dorsal side, which has long transverse wings. A 
median ridge is present, which seems wider near the anterior region of the bone. The posterior margin of the wings is lightly concave.

Osteoderms. A set of osteoderms have been found associated with the skull and mandible. Although they were recovered disconnected, we attempted to reconstruct the corresponding shield (Fig. 9). The first pair of osteoderms has a triangular outline with a truncated anterior corner. To this exception, all other osteoderms are wider than long. In the reconstructed arrangement, which preserves seven rows of paired osteoderms, the width of each element gradually increases backward. All osteoderms maintain a comparable length throughout. The osteoderms contact with their corresponding pair through a median suture. To the exception of the first osteoderms, each osteoderms possesses an articular facet in its anterodorsal margin, which consists of a stripe of smooth bone that inserts below the posterior margin of the preceding osteoderms. To the exception of the osteoderms of the first and second rows, all osteoderms display a developed spine on their anterolateral corner. This spine inserts below a posterolateral expansion of the preceding osteoderm when the shield is interlocked. Here, the osteoderm possesses a median crest on its dorsal surface. Ornamentation consists of ovoid to circular and closely spaced pits on the dorsal surface of the osteoderms. A row of smaller and circular adjacent pits is observed just behind the edge of the articular facet.

\section{Phylogenetic analysis}

Recent analyses recovered a close relationship between Pholidosauridae and Goniopholididae (Martin and Buffetaut, 2012; Martin et al. 2014) but further testing is required because of the lack of Dyrosauridae in these analyses. Here, the 
relationships of Pholidosaurus and Pholidosauridae are explored on the basis of a recent matrix (Pol et al., 2014) that includes all major representatives of neosuchian lineages. New codings for Pholidosaurus are also provided on the basis of the newly described specimens and the presence of Dyrosauridae fills the expectations for a full testing of longirostrine interrelationships. Pholidosaurus from Cherves-de-Cognac was coded in the matrix of Pol et al. (2014) for a total of 110 taxa coded for 412 characters. Two new characters were added (see appendix) thus totalizing 414 characters. In this data matrix, the position of Pholidosaurus is tested against the presence of all the longirostrine lineages including the Eusuchia (Gavialis, Eothoracosaurus and Argochampsa); the Pholidosauridae (Sarcosuchus and Terminonaris); the Dyrosauridae (Dyrosaurus, Chenanisuchus, Rhabdognathus and Sokotosuchus) and Thalattosuchia with both teleosaurids and metriorhynchoids. Other recent works are also relevant, notably in the positioning of Thalattosuchia (e.g. Wilberg, 2015a, b) but characters focus on solving the relationships in this group. Such a new placement for Thalattosuchia is kept in mind here and in some of the tests conducted below, Thalattosuchia are eventually deleted from the analysis, exploring relationships between the remaining longirostrine lineages.

The data matrix was analyzed in TNT (Goloboff, Farris and Nixon, 2003) using a heuristic search with 1000 replicates of Wagner trees (TBR branch swapping). Ordered characters follow the designations in Pol et al. (2014). Bremer decay analyses were conducted as a measure of nodal support and are shown in Figure 9. Because of the abundance of competing hypotheses over the relationships of longirostrine lineages (e.g. Buffetaut, 1982; Benton and Clark, 1988; Buckley and Brochu, 1999; Jouve, 2009; Pol, Turner and Norell, 2009; Wilberg, 2015a, b), convergence and therefore long-branch attraction (LBA) problems in phylogenetic 
analyses are suspected. Therefore, following Bergsten (2005), simple tests of removing/adding clades were conducted. The data matrix is available in the supplementary information.

\subsection{Results}

The analysis of the complete data matrix results in a strict consensus of nine most parsimonious trees (tree length $=1655$; consistency index $=0.302$; retention index $=$ 0.739). As in previous studies (e.g. Pol et al., 2014), the longirostrine non-eusuchians (Thalattosuchia, Dyrosauridae, Pholidosauridae) cluster together in the sister group to derived neosuchians (Atoposauridae, Goniopholididae, Eusuchia). Here, both Pholidosaurus purbeckiensis (NHMUK specimens) and Pholidosaurus from Chervesde-Cognac are included at the base of Pholidosauridae. Removing Thalattosuchia from the analysis yields a strict consensus of 1030 most parsimonious trees (tree length $=1563$; consistency index $=0.319$; retention index $=0.76)$. Here, Pholidosauridae and Dyrosauridae remain grouped together but are now placed in a derived position within the Goniopholididae (Fig. 10A). Removing both Thalattosuchia and Pholidosauridae yields a strict consensus of 870 most parsimonious trees (tree length $=1482$; consistency index $=0.337$; retention index $=$ 0.778). The output is unusual (Fig. 10B) with Dyrosauridae being the sister group of Gavialoidea. Removing Thalattosuchia, Pholidosauridae and Gavialoidea results in a strict consensus of 710 most parsimonious trees (tree length $=1443$; consistency index $=0.346$; retention index $=0.787$ ). Dyrosauridae present an intermediate position between Atoposauridae and derived Neosuchia (i.e. Goniopholididae and Eusuchia) (Fig. 10C). Finally, removing Thalattosuchia and Dyrosauridae results in a strict consensus of 770 most parsimonious trees (tree length $=1532$; consistency 
index $=0.326$; retention index $=0.767$ ). The grouping of Pholidosauridae and Goniopholididae inside Coelognathosuchia is recovered (Fig. 10D), as in previous studies (Martin and Buffetaut, 2012; Martin et al., 2014).

\section{Discussion}

\subsection{Pholidosaurus and the phylogenetic placement of Pholidosauridae}

The phylogenetic placement of non-eusuchian longirostrine taxa (Thalattosuchia, Pholidosauridae, Dyrosauridae) remains contentious. Early studies found evidence for a basal placement of Thalattosuchia (Buffetaut, 1982; Benton and Clark, 1988), which only recently found a phylogenetic support (Wilberg, 2015a, b). Most other phylogenetic hypotheses recovered a grouping of Thalattosuchia, Pholidosauridae and Dyrosauridae in a derived position within Neosuchia (see Jouve et al., 2006). It was also discussed that characters linked to longirostry had no proven influence on such proposed relationships (Pol and Gasparini, 2009) and that such characters were also present in non-longirostrine taxa such as short-snouted dyrosaurids (Hastings et al., 2014). Although the position of Thalattosuchia finds a new alternative at the base of Crocodylomorpha (Wilberg, 2015a, b), the position of Pholidosauridae is still a matter

of discussion (Martin and Buffetaut, 2012; Martin et al., 2014; Young et al., 2014). A number of phylogenetic hypotheses recover Pholidosauridae as the sister group of Dyrosauridae (see Jouve et al., 2006 for a review).

Different manipulations of the data matrix through taxon exclusion/inclusion, reveal that Dyrosauridae have a labile behavior (Fig. 10). Whether Dyrosauridae are excluded or included, the Pholidosauridae always group closely with Goniopholididae. When Pholidosauridae and Dyrosauridae are present in the analysis, both taxa are closely grouped. However, the exclusion of Pholidosauridae from the 
analysis reveals that Dyrosauridae never cluster within Goniopholididae but do group with Gavialoidea, a group of longirostrine eusuchians. In the absence of longirostrine forms (Pholidosauridae or Gavialoidea), the Dyrosauridae sit in an intermediate position between Atoposauridae and derived neosuchians, which seems the most satisfying result when considering the suite of primitive characters (participation of palatines in internal choanae; amphicoelous vertebrae) present in that group. The above tests reveal the presence of LBA in the data matrix. Indeed, improvement over character choice in coding longirostrine specimens requires further work. Although these results are indirect, they show that the current most parsimonious hypothesis is a close relationship of Pholidosauridae with Goniopholididae. Affinities of Pholidosaurus are further discussed below on the basis of comparative anatomy.

\subsection{Affinities with coelognathosuchians}

The affinities of Pholidosauridae with Goniopholididae have been suspected since Buffetaut (1982) but later phylogenetic hypotheses have supported a grouping of Pholidosauridae with Dyrosauridae and Thalattosuchia (see references above).

Although most phylogenetic analyses consistently report a grouping of Pholidosauridae with Dyrosauridae (Buckley and Brochu, 1999; Larsson and Gado, 2000; Brochu et al., 2002; Pol, 2003; Sereno et al., 2003; Pol and Norell, 2004a,b; Pol et al., 2004), synapomorphies for this clade are not presented. When synapomorphies are discussed, they do not diagnose Dyrosauridae + Pholidosauridae because of the involvement of Thalattosuchia (e.g. Jouve et al., 2006). One exception is found in the work of Wu et al. (2001), who concluded that Pholidosauridae and Dyrosauridae were closely related and found support for this relationship on the basis of three unambiguous synapomorphies: 1) premaxilla broad anterior to nares, similar in width 
to the lateral part to the naris; 2) postorbital with a pronounced anterolateral process; 3) internal choana subdivided. However, the definition of the relative width of the premaxilla is vague; the anterolateral process of the postorbital is observed in another unrelated but convergent longirostrine group, the Gavialoidea; the subdivision of the interal choana by a lamina is variably observed in eusuchians. There is however, growing evidence that Thalattosuchia occupy a basal position within Crocodylomorpha (e.g. Wilberg, 2015a, b). For this reason, the below comparison is restricted to Pholidosauridae, Dyrosauridae and Goniopholididae (Owen, 1878; Lortet, 1892; Mook, 1934; de Broin and Taquet, 1966; Buffetaut, 1978, 1982; Wu et al., 2001; de Lapparent de Broin, 2002; Jouve et al., 2006; Hua et al., 2007; RaslanLoubatié, 2007; Lauprasert et al., 2007; Barbosa, Kellner and Vianna, 2008; Smith et al., 2010; Salisbury and Naish, 2011; Fortier, Perea and Schultz, 2011; Andrade et al., 2011; Hastings, Bloch and Jaramillo, 2014; Martin et al., 2014).

The shape of the premaxilla of Pholidosaurus, expanding laterally from the premaxillary-maxillary notch and comprising 5 alveoli arranged in a semi-circular fashion is not comparable to that of Dyrosauridae. In these taxa, the premaxilla is in line with the maxilla with a moderate notching at the premaxillary-maxillary level and comprises 4 alveoli that are nearly aligned with the maxillary tooth row.

Pholidosaurus and Goniopholis from Cherves-de-Cognac, Goniopholis crassidens, Goniopholis kiplingi, Goniopholis willetti, Siamosuchus phuphokensis, Sarcosuchus imperator, Chalawan thailandicus, Elosuchus cherifiensis, Meridiosaurus vallisparadisi, Oceanosuchus boecensis, Terminonaris robusta all have 5 premaxillary alveoli. The arrangement of the premaxillary alveoli resembles that of Elosuchus cherifiensis and goniopholidids and is not forming the true transverse 
‘beak’ observed in Sarcosucus, Terminonaris, Meridiosaurus, Oceanosuchus or Crocodilaemus.

The maxillary alveolar count of Dyrosauridae (G. muzini = 12-13; Arambourgisuchus $=17 ;$ D. maghribiensis $=19-21)$ is smaller than in most Pholidosauridae with Sarcosuchus imperator, Chalawan thailandicus and Meridiosaurus vallisparadisi approaching 30 or even nearly 40 alveoli in $T$. robusta (Mook, 1934). On the other hand, Pholidosaurus from Cherves-de-Cognac possesses a maximum of 23 alveoli, a count closer to that of some goniopholidids such as Goniopholis from Cherves-de-Cognac with at least 21 (Raslan-Loubatié, 2007), or G. willetti, which possesses at least 24 alveoli (Salisbury and Naish, 2011). The count in G. simus is unknown (Salisbury et al., 1999) and a CT scan showed 19 alveoli in the maxilla of G. kiplingi (Andrade et al., 2011), which is similar to the count in Dollo's goniopholidid (JEM, pers. obs.).

The outline of the posterior margin of the pterygoid wing of Dyrosauridae resembles that of eusuchians. In both cases, it is mediolaterally oriented and can be straight or slightly concave (compare any species of Crocodylus with Fig. 19 in Jouve et al., 2006). This is unlike the configuration of the posterior margin of the pterygoid wing in Pholidosauridae. In Pholidosaurus from Cherves-de-Cognac, the posterolateral edge of the pterygoid wing is located anteriorly to the posteromedial edge (Fig. 2) as is the case in Sarcosuchus imperator, Terminonaris robusta, Crocodilaemus robustus. This morphology is not well preserved among goniopholidids but can be observed in Dollo's goniopholidid from Bernissart.

The ectopterygoid is not often well preserved or visible in Dyrosauridae. In cf. Rhabdognathus, its margin contributing to the suborbital fenestra is concave (Fig. 2 in Brochu et al., 2002) as is the case in Eusuchians. This is contrasting with 
Pholidosaurus from Cherves-de-Cognac, in which the margin contributing to the suborbital fenestra is convex. Such examples can be observed in goniopholidids such as Dollo's specimen from Bernissart (JEM, Pers. Obs.), in G. willetti (Salisbury and Naish, 2011) and in G. kiplingi according to the CT scan provided in Andrade et al. (2011). In pholidosaurids, this feature can be observed in Sarcosuchus imperator and Terminonaris robusta.

The internal choana in Dyrosauridae has a subcircular to triangular outline that opens near the posterior edge of the palate (e.g. Brochu et al., 2002; Jouve et al., 2006; Barbosa et al., 2008). Although the palatines contribute to the anterior margin of the choana, its outline and extension is not comparable to that of Pholidosaurus from Cherves-de-Cognac. In Pholidosaurus, the choana strongly resembles that of goniopholidids, which are longer than wide and project anteriorly on the palatine bar between the suborbital fenestrae as in G. willetti, A. hooleyi, E. delfsi. The internal choana of Sarcosuchus and Terminonaris is not as elongate as that of Pholidosaurus/Goniopholididae and is about as long as wide.

The postorbital bar of Pholidosaurus from Cherves-de-Cognac (Fig. 4) has a distinct shape that recalls the morphology described in the longirostrine goniopholidid Vectisuchus leptognathus (Buffetaut and Hutt, 1980; Salisbury and Naish, 2011, textfigure 24.13).

The cranioquadrate passage of cf. Rhabdognathus is bounded by the quadrate and exoccipital and is visible in posterior view (Brochu et al., 2002). This condition is rather similar to that seen in eusuchians. On the other hand, the cranioquadrate passage is laterally open in Pholidosaurus from Cherves-de-Cognac, with no contact observed between the paroccipital process, the squamosal and quadrate, a condition similar in goniopholidids such as G. simus (Salisbury et al., 1999), G. baryglyphaeus 
(Schwarz, 2002), G. willetti (Salisbury and Naish, 2011) but also in pholidosaurids such as S. imperator, E. cherifiensis and C. thailandicus (Martin et al., 2014).

The morphology of the maxillojugal depression was reviewed in Martin and Buffetaut (2012), who established that Pholidosaurus from Cherves-de-Cognac resembles that of Goniopholididae in its position. In other Pholidosauridae, the maxillojugal depression is positioned both on the posterior margin of the maxilla and on the anterior margin of the jugal.

In Dyrosauridae, the dentary alveoli are well spaced and homodont to the exception of the $7^{\text {th }}$, which is significantly smaller than other alveoli and positioned close to the $8^{\text {th }}$ alveolus (e.g. Buffetaut, 1980). In Pholidosaurus from Cherves-deCognac, the $3^{\text {rd }}$ and $4^{\text {th }}$ alveoli are confluent and enlarged, a condition observed in goniopholidids such as G. baryglyphaeus (Schwarz, 2002), G. crassidens (Owen, 1878; Salisbury, 2002). In Elosuchus cheriffiensis (Lapparent de Broin, 2002; Fig. $2 \mathrm{D})$, the $2^{\text {nd }}$ and $3^{\text {rd }}$ are displaced laterally. In other pholidosaurids, the $3^{\text {rd }}$ and $4^{\text {th }}$ alveoli are the largest in Sarcosuchus and Chalawan, but they are not confluent but closely spaced to each other with the $4^{\text {th }}$ being the largest.

As reviewed in Martin (2015), the dorsal shield of pholidosaurids and goniopholidids is made of mediolaterally elongate osteoderms bearing an anterolateral spine. This is distinct from that of dyrosaurids, which are subrectangular in outline and do not show the anterolateral spine.

In conclusion, Pholidosaurus purbeckensis shares a number of characters with other Pholidosauridae and Goniopholididae, and synapomorphies with the latter forms support the monophyletic nature of Coelognathosuchia. Moreover, P. purbeckensis does not share these same characters with Dyrosauridae, going against the hypothesis 
that Dyrosauridae and Pholidosauridae have more in common than do Pholidosauridae with Goniopholididae.

\subsection{Palaeoecology}

Pholidosaurus from Cherves-de-Cognac was recovered in close association with numerous remains of Goniopholis sp. (Raslan-Loubatié, 2007) and also with rare remains of Theriosuchus sp. and Bernissartia cf. fagesii (Pouech et al., 2006). Were these species sharing the same habitat and if so, how did they partition food resources? Such diverse assemblages have also been reported from the Purbeck Limestone Group (e.g. Salisbury and Naish, 2011) and anatomical evidence served as a start to understand that the ecology of these different species should have differed. The genus Theriosuchus is viewed as a possible terrestrial taxon (e.g. Schwarz and Salisbury, 2005), a view supported because of the construction of its skull (Martin et al., 2014a). The other three taxa are aquatic and the geochemical evidence mentioned below points to a freshwater habitat. Today, coexistence of multiple crocodilian taxa in a same environment implies resource partitioning or spatial segregation along the river or lake by body size or due to microhabitat preference (Webb, Manolis and Sack, 1983; Heron, 1994). All may have been mainly piscivores but the small $B$. cf. fagesii may have specialized toward hard-shelled preys (Mazin et al., 2008) and Goniopholis may have ambushed terrestrial vertebrates when reaching a certain size, similar to observations made on Crocodylus niloticus (Cott, 1961). The slendersnouted Pholidosaurus is expected to feed almost exclusively on fish. There is very little work on the interactions between extant longirostrine versus mesorostrine forms in a same habitat. In India, Gavialis gangeticus and Crocodylus palustris inhabit the same streams and species competition is suspected but not confirmed (Da Silva and 
Lenin, 2010). In West Africa, Mecistops cataphractus and Crocodylus niloticus can be found in the same areas (e.g. Shirley, 2010) but we are not aware of ethological studies on possible interactions. That Pholidosaurus avoided contact from the larger, potentially dangerous Goniopholis seems plausible given that body size plays a role in habitat segregation of sympatric species (Webb et al., 1983; Farlow and Pianka, 2002).

Pholidosaurus from Cherves-de-Cognac was recovered from non-marine sediments in a littoral context indicating a hypersaline lagoonal environment (El Albani et al., 2004; Mazin et al., 2008; Pouech et al., 2014). Geochemical analysis of the vertebrate assemblage concluded that Pholidosaurus as well as other crocodilians found at that site (Goniopholis sp., Theriosuchus sp. and Bernissartia cf. fagesii.) are allochtonous and their remains were accumulated during a flooding event (Pouech et al., 2014) indicating these animals were restricted to a nearby freshwater environment. Although no geochemical analyses have been conducted on the crocodilian assemblages from the Purbeck Limestone Group of England or from the Obernkirchen Sandstone of north-western Germany, the lithology and depositional environments are similar to those of Cherves-de-Cognac and invite to consider these crocodilians to be of allochtonous origin too. Other pholidosaurids have demonstrated occurrences in freshwater deposits such as Elosuchus cherifiensis from the Albian of Morocco (Lapparent de Broin, 2002), Meridiosaurus vallisparadisi from the Late Jurassic of Uruguay, (Fortier et al., 2011) Sarcosuchus imperator from the AptianAlbian of Niger (Broin and Taquet, 1966), Sarcosuchus sp. from the ?Aptian of Brazil (Buffetaut and Taquet, 1977) and Chalawan thailandicus from the early Cretaceous of Thailand (Martin et al., 2014). The Pholidosauridae otherwise contain taxa recovered in marine environments such as Oceanosuchus boecensis from the 
Cenomanian of France (Hua et al., 2007), Terminonaris robusta and T. browni from the Albian-Cenomanian of North America (Wu et al., 2001; Adams et al., 2011) and Terminonaris sp. from the Cenomanian of Germany (Buffetaut and Wellnhofer, 1980). Wu et al. (2001) found it unusual to find Terminonaris so far from shore and did not exclude the possibility that the carcass, despite being articulated, could have floated for some time. Another hypothesis drew a parallel between the sea going capacities of today's Crocodylus porosus and Terminonaris (Hua and Buffetaut, 1997). The ability of Pholidosauridae to migrate between different types of environments is a hypothesis considered likely given the paleogeographical context and the close affinities of Sarcosuchus from Brazil-Niger with Chalawan from Thailand (Martin et al., 2014).

\subsection{Concluding remarks}

We have described new and relatively complete cranial remains referable to Pholidosaurus purbeckensis from the lower Cretaceous of Charente, France. These specimens represent the most complete individuals of that species to date, and for this reason help to further our understanding of the anatomy of this longirostrine mesoeucrocodylian. In updating its phylogenetic coding, we addressed the issue of morphological convergence in longirostrine forms, which have often been grouped together under previous hypotheses. Although further work will be necessary, we preliminary exclude a close relationship between pholidosaurids and dyrosaurids and invite to consider the Coelognathosuchia (i.e. Pholidosauridae + Goniopholididae) as monophyletic, represented by mesoeucrocodylians with diverse snout morphologies. Pholidosaurus living in sympatry with other species has been evoked and the capacity 
of pholidosaurids to live in marine environments could explain its nearly global distribution during the Cretaceous.

\section{Acknowledgements}

We would like to thank Thierry Lenglet and staff at the Musée d'Angoulême for facilitating our study of the specimens. The Garandeau group at the Champblanc quarry is also duly thanked for allowing excavations that led to the discovery of specimens reported in this work. Several volunteers including students provided much help during fieldwork. JEM thanks L. Steel (NHMUK, London) for access to comparative Pholidosaurus material in her care. C. Brochu, A. Ösi and the editor E. Koutsoukos provided constructive comments that helped improve the quality of this work.

\section{References}

Adams, T.S., Polcyn, M.J., Mateus, O., Winkler, D.A., Jacobs, L.L., 2011. First occurrence of the long-snouted crocodyliform Terminonaris (Pholidosauridae) from the Woodbine Formation (Cenomanian) of Texas. Journal of Vertebrate Paleontology 31, 712-716.

Andrade, M.B., Edmonds, R., Benton, M.J., Schouten, R., 2011. A new Berriasian species of Goniopholis (Mesoeucrocodylia, Neosuchia) from England, and a review of the genus: new Goniopholis from England. Zoological Journal of the Linnean Society 163, S66-S108.

Andrews, C.W., 1913. On the skull and part of the skeleton of a crocodile from the middle Purbeck of Swanage, with a description of a new species 
(Pholidosaurus laevis, and a note on the skull of Hylaeochampsa. The annals and magazine of natural history $11,485-494$.

Barbosa, J.A., Kellner, A.W.A., Vianna, M.S.S., 2008. New dyrosaurid crocodylomorph and evidences for faunal turnover at the K-P transition in Brazil. Proceedings of the Royal Society B: Biological Sciences 275, 13851391.

Benton, M.J., Clark, J.M., 1988. 8. Archosaur phylogeny and the relationships of the Crocodylia. The Phylogeny and Classification of the Tetrapods. Oxford: Clarendon Press, 295-338.

Bergsten, J., 2005. A review of long-branch attraction. Cladistics 21, 163-193.

Billon-Bruyat, J-P., 2003. Les écosystèmes margino-littoraux du Jurassique terminal et Crétacé basal d'Europe Occidentale: biodiversité, biogéochimie et l'événement biotique de la limite Jurassique/Crétacé. Unpublished PhD Thesis, Université de Poitiers, 254 pp.

Brochu, C.A., Bouaré, M., Sissoko, F., Roberts, E.M., O’Leary, M.A., 2002. A dyrosaurid crocodyliform braincase from Mali. Journal of Paleontology 76, 1060-1071.

Broin, F., de, Taquet, P., 1966. Découverte d'un crocodilien nouveau dans le Crétacé inférieur du Sahara. Comptes Rendus de l'Académie des Sciences 262, 23262329.

Buckley, G.A., Brochu, C.A., 1999. An enigmatic new crocodile from the Upper Cretaceous of Madagascar. Special Papers in Palaeontology 60, 149-175. 
Buffetaut, E., Hutt, S., 1980. Vectisuchus leptognathus, n.g., n.sp., a slender-snouted goniopholid crocodilian from the Wealden of the Isle of Wight. Neues Jahrbuch für Geologie und Paläeontologie, Monatshefte 7, 385-390.

Buffetaut, E., 1980. Les crocodiliens Paléogènes du Tilemsi (Mali): un aperçu systématique. Palaeovertebrata, Mémoire jubilaire en hommage à René Lavocat, $15-35$.

Buffetaut, E., 1982. Radiation évolutive, paléoécologie et biogéographie des crocodiliens mésosuchiens. Mémoires de la Société Géologique de France $142,1-88$.

Buffetaut, E., Taquet, P., 1977. The giant crocodilian Sarcosuchus in the early Cretaceous of Brazil and Niger. Palaeontology 20, 203-208.

Buffetaut, E., 1978. Les Dyrosauridae (Crocodylia, Mesosuchia) des phosphates de l'Eocène inférieur de Tunisie: Dyrosaurus, Rhabdognathus, Phosphatosaurus. Géologie Méditerranéenne 5, 237-256.

Buffetaut, E., Pouit, D., Rigollet, L., Archambeau, J-P., 1989. Poissons et reptiles continentaux du Purbeckien de la région de Cognac (Charente). Bulletin de la Société Géologique de France 5, 1065-1069.

Buffetaut, E., Wellnhofer, P., 1980. Der Krokodilier Teleorhinus Osborn, 1904 (Mesosuchia, Pholidosauridae) im Regensburger Grünsandstein (Obercenoman). Mitteilungen Bayerische Staatssammlung für Paläontologie und Historische Geologie 20, 83-94.

Colin, J-P., El Albani, A., Fürsich, F.T., Martin-Closas, C., Mazin, J-M., BillonBruyat J-P., 2004. Le gisement "Purbeckien" de vertébrés de Cherves-de- 
Cognac, Charente (SW France): nouvelles données biostratigraphiques. Comptes Rendus Palevol 3: 9-16.

Coquand, H., 1858. Description physique, géologique, paléontologique et minéralogique du département de la Charente, Tome premier. Dodivers et Cie, Besançon, 542pp.

Coquand, H., 1860. Description physique, géologique, paléontologique et minéralogique du département de la Charente, Tome deuxième. Barlatier-Feissat et Demonchy, Marseille, 420pp.

Cott, H.B., 1961. Scientific results of an inquiry into the ecology and economic status of the Nile Crocodile (Crocodylus niloticus) in Uganda and Northern Rhodesia. Transactions of the zoological Society of London 29, 211-357.

El Albani, A., Fürsich, F.T., Colin, J.P., Meunier, A., Hochuli, P., Martin-Closas, M., Mazin, J.M., Billon-Bruyat, J.P., 2004. Palaeoenvironmental reconstruction of the basal Cretaceous vertebrate bearing beds in the Northern part of the Aquitaine Basin (SW France): sedimentological and geochemical evidence. Facies 50, 195-215.

Farlow, J.O., Pianka, E.R., 2002. Body Size Overlap, Habitat Partitioning and Living Space Requirements of Terrestrial Vertebrate Predators: Implications for the Paleoecology of Large Theropod Dinosaurs. Historical Biology 16, 21-40.

Fortier, D., Perea, D., Schultz, C., 2011. Redescription and phylogenetic relationships of Meridiosaurus vallisparadisi, a pholidosaurid from the Late Jurassic of Uruguay. Zoological Journal of the Linnean Society 163, 257-272. 
Goloboff, P.A., Farris, J.S., Nixon, K., 2003. TNT: tree analysis using new technologies (Program and documentation available from the authors and at http:www.zmuc.dk/public/phylogeny).

Hastings, A.K., Bloch, J.I., Jaramillo, C.A., 2014. A new blunt-snouted dyrosaurid, Anthracosuchus balrogus gen. et sp. nov. (Crocodylomorpha, Mesoeucrocodylia), from the Palaeocene of Colombia. Historical Biology 27, $998-1020$.

Heron, J.C., 1994. Body size, spatial distribution, and microhabitat use in the caimans, Melanosuchus niger and Caiman crocodilus, in a Peruvian lake. Journal of Herpetology 28: 508-513.

Hervat, P., Hervat, M., 1993. Découverte de Polyacrodus parvidens (Woodward, 1916) (Elasmobranchii, Hybodontoidea) dans un faciès purbeckien (Tithonien supérieur) du Charentais (France). Cossmanniana, hors série 2: 43-48.

Hua, S., Buffetaut, E., 1997. Crocodylia. In: Callaway JM, Nicholls EL, eds. Ancient marine reptiles. San Diego: Academic Press, 357-374.

Hua, S., Buffetaut, E., Legall, C., Rogron, P., 2007. Oceanosuchus boecensis n. gen, n. sp., a marine pholidosaurid (Crocodylia, Mesosuchia) from the Lower Cenomanian of Normandy (western France). Bulletin de la société géologique de France 178, 503-513.

Iordansky, N.N., 1973. The skull of the Crocodylia. In: Gans C, Parson TS, eds. Biology of the Reptilia, vol. 1, morphology A. London and New York: Academic Press, 201-262. 
Jouve, S., 2009. The skull of Teleosaurus cadomensis (Crocodylomorpha;

Thalattosuchia), and phylogenetic analysis of Thalattosuchia. Journal of Vertebrate Paleontology 29, 88-102.

Jouve, S., Iarochene, M., Bouya, B., Amaghzaz, M., 2006. A new species of Dyrosaurus (Crocodylomorpha, Dyrosauridae) from the early Eocene of Morocco: phylogenetic implications. Zoological Journal of the Linnean Society $148,603-656$.

de Lapparent de Broin, F., 2002. Elosuchus, a new genus of crocodile from the Lower Cretaceous of the North of Africa. Comptes Rendus Palevol 1, 275-285.

Larsson, H.C.E., Gado, B., 2000. A new Early Cretaceous crocodyliform from Niger. Neues Jahrbuch für Geologie und Paläontologie, Abhandlungen 217, 131-141.

Lauprasert, K., Cuny, G., Buffetaut, E., Suteethorn, V., Thirakhupt, K., 2007.

Siamosuchus phuphokensis, a new goniopholidid from the Early Cretaceous (ante-Aptian) of northeastern Thailand. Bulletin de la Société Géologique de France 178, 201-216.

Le Loeuff, J., Buffetaut, E., Merser, C., 1996. Découverte d'un dinosaure sauropode tithonien dans la région de Cognac (Charente). Géologie de la France, 2, 7981.

Lortet, L., 1892. Les reptiles du bassin du Rhône. Archives du Muséum d’Histoire Naturelle de Lyon 5, 3-133.

Mansel-Pleydell, J.C., 1888. Fossil reptiles of Dorset. Proceedings of the Dorset Natural History and Antiquarian Field Club 9, 1-40. 
Martin, J.E., 2015., A sebecosuchian in a middle Eocene karst with comments on the dorsal shield in Crocodylomorpha. Acta Palaeontologica Polonica 60, 673680.

Martin, J.E., Rabi, M., Csiki-Sava, Z., Vasile, S., 2014a. Cranial morphology of Theriosuchus sympiestodon (Mesoeucrocodylia, Atoposauridae) and the widespread occurrence of Theriosuchus in the Late Cretaceous of Europe. Journal of Paleontology 88, 444-456.

Martin, J.E., Buffetaut, E., 2012. The maxillary depression of Pholidosauridae: an anatomical study. Journal of Vertebrate Paleontology 32, 1442-1446.

Martin, J.E., Lauprasert, K., Buffetaut, E., Liard, R., Suteethorn, V., 2014b. A large pholidosaurid in the Phu Kradung Formation of north-eastern Thailand (K Angielczyk, Ed.). Palaeontology 57, 757-769.

Mazin, J-M., Billon-Bruyat, J-P., Pouech, J. and Hantzpergue P., 2006. The Purbeckian site of Cherves-de-Cognac (Berriasian, Early Cretaceous, Southwest France): a continental ecosystem accumulated in an evaporitic littoral depositional environment. In Barret P., Evans S. (Eds), 9th Mesozoic Terrestrial Ecosystems and Biota, Manchester, Abstracts Volume: 84-88.

Mazin, J.M., Pouech, J., Hantzpergue, P., Lenglet, T., 2008. The Purbeckian site of Cherves-de-Cognac (Beriasian, Early Cretaceous, SW France): a first synthesis. Documents STU Lyon. Mid-Mesozoic Life and Environments 164, $68-71$ 
Meyer, H. von., 1841. Pholidosaurus schaumbergensis, ein saurus aus dem sandstein der Wald-Formation Nord-Deutschlands. Neues Jahrbuch für Mineralogie, Geognosie, Geologie und Petrefakten-Kunde 1841, 343-345.

Meyer, H. von., 1846. Reptilien aus der Wealdenformation Norddeutschlands. Monographie der Norddeutschen Wealdenbildung. Braunschweig, 83.

Mook, C.C., 1934. A new species of Teleorhinus from the Benton Shales. American Museum Novitates 702, 1-11.

Owen, R., 1878. Monograph on the fossil Reptilia of the Wealden and Purbeck formations. Monograph of the Palaeontological Society 32, 1-15.

Pol, D., 2003. New remains of Sphagesaurus huenei (Crocodylomorpha: Mesoeucrocodylia) from the Late cretaceous of Brazil. Journal of Vertebrate Paleontology 23, 817-831.

Pol, D., Ji, S., Clark, J.M., Chiappe, L.M., 2004. Basal crocodyliforms from the $<$ Lower Cretaceous Tugulu Group (Xinjiang, China), and the phylogenetic position of Edentosuchus. Cretaceous Research 25, 603-622.

Pol, D., Norell, M.A., 2004a. A new crocodyliform from Zos Canyon, Mongolia. American Museum Novitates 3445, 1-36.

Pol, D., Norell, M.A., 2004b. A new gobiosuchid crocodyliform taxon from the Cretaceous of Mongolia. American Museum Novitates 3458, 1-31.

Pol, D., Turner, A.H., Norell, M.A., 2009. Morphology of the Late Cretaceous crocodylomorph Shamosuchus djadochtaensis and a discussion of neosuchian 
phylogeny as related to the origin of Eusuchia. Bulletin of the American Museum of Natural History 324, 1-103.

Pol, D., Gasparini, Z., 2009. Skull anatomy of Dakosaurus andiniensis (Thalattosuchia: Crocodylomorpha) and the phylogenetic position of Thalattosuchia. Journal of Systematic Palaeontology 7, 163-197.

Pol, D., Nascimento, P.M., Carvalho, A.B., Riccomini, C., Pires-Domingues, R.A., Zaher, H., 2014. A New Notosuchian from the Late Cretaceous of Brazil and the Phylogeny of Advanced Notosuchians (L Claessens, Ed.). PLoS ONE 9, e93105.

Pouech J. 2008. Position des Mammifères dans les écosystèmes mésozoïques d'Europe Occidentale: Le site de Cherves-de-Cognac (Berriasien, Charente, France). Unpublished PhD Thesis, Université Lyon 1, 311 pp., 89 figs, 89 pl. Pouech, J., Amiot, R., Lécuyer, C., Mazin, J.M., Martineau, F., Fourel, F., 2014. Oxygen isotope composition of vertebrate phosphates from Cherves-deCognac (Berriasian, France): environmental and ecological significance. Palaeogeography Palaeoclimatology Palaeoecology 410, 290-299.

Raslan-Loubatié, J., 2007. La place des Goniopholididae et des Pholidosauridae au sein des Neosuchia (Crocodyliformes). Master's thesis, Université Claude Bernard Lyon 1 and Museum National d'Histoire Naturelle, 31 pp.

Salisbury, S.W., Molnar, R.E., Frey, E., Willis, P.M., 2006. The origin of modern crocodyliforms: new evidence from the Cretaceous of Australia. Proceedings of the Royal Society B: Biological Sciences 273, 2439-2448. 
Salisbury, S.W., 2002. Crocodilians from the lower Cretaceous (Berriasian) Purbeck Limestone Group of Dorset, Southern England. Special Papers in Palaeontology 68, 121-144.

Salisbury, S.W., Frey, E., Martill, D., Buchy, M.C., 2003. A new crocodilian from the Lower Cretaceous Crato Formation of north-eastern Brazil. Palaeontographica Abteilung A, Palaozoologie-Stratigraphie 270, 3-47.

Salisbury, S.W., Naish, D., 2011. Crocodilians. English Wealden Fossils. London, $305-369$.

Salisbury, S.W., Willis, P.M.A., Peitz, S., Sander, P.M., 1999. The crocodilian Goniopholis simus from the lower Cretaceous of north-western Germany. Special Papers in Palaeontology 60, 121-148.

Schwarz, D., 2002. A New Species of Goniopholis from the Upper Jurassic of Portugal. Palaeontology 45, 185-208.

Schwarz, D., Salisbury, S.W., 2005. A new species of Theriosuchus (Atoposauridae, Crocodylomorpha) from the Late Jurassic (Kimmeridgian) of Guimarota, Portugal. Geobios 38, 779-802.

Sereno, P.C., Larsson, H.C., Sidor, C.A., Gado, B., 2001. The Giant Crocodyliform Sarcosuchus from the Cretaceous of Africa. Science 294, 1516-1519.

Sereno, P.C., Sidor, C.A., Larsson, H.C.E., Gado, B., 2003. A new notosuchian from the Early Cretaceous of Niger. Journal of Vertebrate Paleontology 23, 477482. 
Shirley, M.H., 2010. Slender-snouted Crocodile Crocodylus cataphractus. Third Edition. Crocodiles. Status Survey and Conservation Action Plan. Darwin: Crocodile Specialist Group, 54-58.

Da Silva, A., Lenin, J., 2010. Mugger Crocodile Crocodylus palustris. Third Edition. Crocodiles. Status Survey and Conservation Action Plan. Darwin: Crocodile Specialist Group, 94-98.

Smith, D.K., Allen, E.R., Sanders, R.K., Stadtman, K.L., 2010. A new specimen of Eutretauranosuchus (Crocodyliformes; Goniopholididae) from Dry Mesa, Colorado. Journal of Vertebrate Paleontology 30, 1466-1477.

Turner, A.H., 2015. A Review of Shamosuchus and Paralligator (Crocodyliformes, Neosuchia) from the Cretaceous of Asia. PLoS ONE 10, e0118116.

Turner, A.H., Pritchard, A.C., 2015. The monophyly of Susisuchidae (Crocodyliformes) and its phylogenetic placement in Neosuchia. PeerJ 3, e759.

Watson, D.M.S., 1911. Notes on some British Mesozoic crocodiles. Memoirs and Proceedings of the Manchester Literary and Philosophical Society 55, 1-13.

Webb, G.J.W., Manolis, S.C., Sack, G.C., 1983. Crocodylus johnstoni and C. porosus coexisting in a tidal river. Wildlife Research 10, 639-650.

Whetstone, K.N., Whybrow, P.J., 1983. A 'cursorial' crocodilian from the Triassic of Lesotho (Basutoland), southern Africa. Occasional Papers of the Museum of Natural History, University of Kansas 106, 1-37. 
Wilberg, E.W., 2015a. What's in an Outgroup? The Impact of Outgroup Choice on the Phylogenetic Position of Thalattosuchia (Crocodylomorpha) and the Origin of Crocodyliformes. Systematic Biology 64: 621-631.

Wilberg, E.W., 2015b. A new metriorhynchoid (Crocodylomorpha, Thalattosuchia) from the Middle Jurassic of Oregon and the evolutionary timing of marine adaptations in thalattosuchian crocodylomorphs. Journal of Vertebrate Paleontology 35, e902846.

Wu, X.C., Russell, A.P., Cumbaa, S.L., 2001. Terminonaris (Archosauria: Crocodyliformes): new material from Saskatchewan, Canada, and comments on its phylogenetic relationships. Journal of Vertebrate Paleontology 21, 492514.

Young, M.T., Steel, L., Foffa, D., Price, T., Naish, D., Tennant, J.P., 2014. Marine tethysuchian crocodyliform from the ?Aptian-Albian (Lower Cretaceous) of the Isle of Wight, UK: Cretaceous Tethysuchian from UK. Biological Journal of the Linnean Society 113, 854-871.

Zittel, K.A., Eastman, C.R., 1902. Text-book of palaeontology. London.

\section{Figure captions}

Figure. 1. The gypsum quarry of Champblanc is located near the village of Chervesde-Cognac, in the vicinity of the town of Cognac (Département de la Charente, South Western France). (Single column) 
Figure 2. The skull of Pholidosaurus purbeckensis (CHV03.100) from the Berriasian of Cherves-de-Cognac, France in dorsal view. A, photograph and B, corresponding line drawing. Scale bar equals $10 \mathrm{~cm}$. Abbreviations: en, external nares; f, frontal; $\mathrm{j}$, jugal; 1, lacrimal; 1tf, lower temporal fenestra; ls, laterosphenoid; mx, maxilla; mxd, maxillary depression; $\mathrm{n}$, nasal; or, orbit; $\mathrm{p}$, parietal; pf, prefrontal; pmx, premaxilla; po, postorbital; pt, pterygoid; q, quadrate; qj, quadratojugal; stf, supratemporal fenestra; sq, squamosal. (2-column)

Figure 3. The skull of Pholidosaurus purbeckensis (CHV03.100) from the Berriasian of Cherves-de-Cognac, France in dorsal view. A, photograph and B, corresponding line drawing. Scale bar equals $10 \mathrm{~cm}$. Abbreviations: boc, basioccipital; ch, choanae; ec, ectopterygoid; f, frontal; j, jugal; 1, lacrimal; 1tf, lower temporal fenestra; ls, laterosphenoid; mx, maxilla; oc, occipital condyle; pa, palatine; pmx, premaxilla; po, postorbital; q, quadrate; qj, quadratojugal; sof, suborbital fenestra; sq, squamosal; A, A', B, B', D: crests for muscle attachment (Iordansky, 1973). (2-column)

Figure 4. The skull of Pholidosaurus purbeckensis (TL) from the Berriasian of Cherves-de-Cognac, France in A, dorsal and B, ventral views. Abbreviations: ec, ectopterygoid; f, frontal; j, jugal; 1, lacrimal; ltf, lower temporal fenestra; mx, maxilla; n, nasal; oc, occipital condyle; or, orbit; pa, palatine; pmx, premaxilla; po, postorbital; q, quadrate; qj, quadratojugal; sof, suborbital fenestra; sq, squamosal. (2-column)

Figure 5. The skull of Pholidosaurus purbeckensis (CHV03.100) from the Berriasian of Cherves-de-Cognac, France in A, lateral view. Close-ups show B, the antorbital area and $\mathrm{C}$, the postorbital region with $\mathrm{D}$, associated line drawing. The white arrows 
follow the maxilla-lacrimal suture. Abbreviations: j, jugal; 1, lacrimal; ltf, lower temporal fenestra; mx, maxilla; mxd, maxillary depression; or, orbit; po, postorbital; sq, squamosal; stf, supratemporal fenestra. (2-column)

Figure 6. The skull of Pholidosaurus purbeckensis (CHV03.100) from the Berriasian of Cherves-de-Cognac, France in occipital view. A, photograph and B, associated line drawing. Abbreviations: boc, basioccipital; bsph, basisphenoid; cqg, cranioquadrate groove; exo, exoccipital; fcp, foramen caroticum posterius; fv, foramen vagus; q, quadrate; soc, supraoccipital; soc.s., supraoccipital spine; sq, squamosal. (1.5-column)

Figure 7. The mandibular rami of Pholidosaurus purbeckensis (CHV03.100) from the Berriasian of Cherves-de-Cognac, France in A, occlusal view. B, ventral view of the posterior end of the right ramus. Close-up of the anterior end of the left ramus in C, occlusal and D, left lateral views, showing the confluent third and fourth alveoli. The posterior end of the left mandibular ramus in $\mathrm{E}$, left lateral view with $\mathrm{F}$, associated line drawing showing the external mandibular fenestra. Abbreviations: an, angular; art, articular; den, dentary; emf, external mandibular fenestra; h, hook on dorsal surface of retroarticular process; $\mathrm{k}$, knob on surangular for muscle scar; Mptp, Musculus pterygoideus posterior; san, surangular; sp, splenial; sps, splenial symphysis. (2-column)

Figure 8. 3D rendered image of an isolated tooth of Pholidosaurus purbeckensis from the Berriasian of Cherves-de-Cognac, France in A, lingual; B, labial; C, D, mesial or distal; E, apical and F, basal views. Scale bar is $1 \mathrm{~mm}$. (single column) 
Figure 9. The anterior region of the dorsal shield of Pholidosaurus purbeckensis (CHV03.100) from the Berriasian of Cherves-de-Cognac. Abbreviations: af, articular facet; als, anterolateral spine. (1.5-column)

Figure 10. Summary of the LBA tests for the phylogenetic hypotheses on the position of Pholidosauridae and Pholidosaurus. Strict consensus trees A, without Thalattosuchia; B, without Thalattosuchia, Pholidosauridae; C, without Thalattosuchia, Pholidosauridae and Gavialoidea; D, without Thalattosuchia, Dyrosauridae. (1.5-column)

\section{Appendix.}

Character 413. Jugal contributes to lateral margin of suborbital fenestra and prevents anterior process of ectopterygoid to meet maxilla (0), or jugal excluded from lateral margin of suborbital fenestra and ectopterygoid contacts maxilla (1), or extensive contact between ectoptergoid and maxilla at the level of the posterior maxillary tooth row (2).

Character 414. Suborbital margin of anterior process of ectopterygoid in ventral view: convex (0); concave (1). 


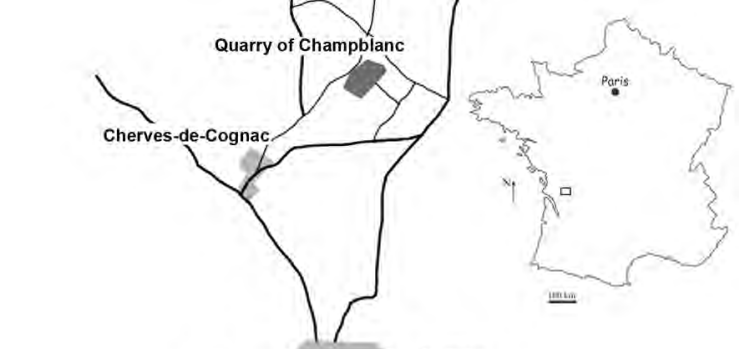

\section{Cognac}

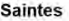


A

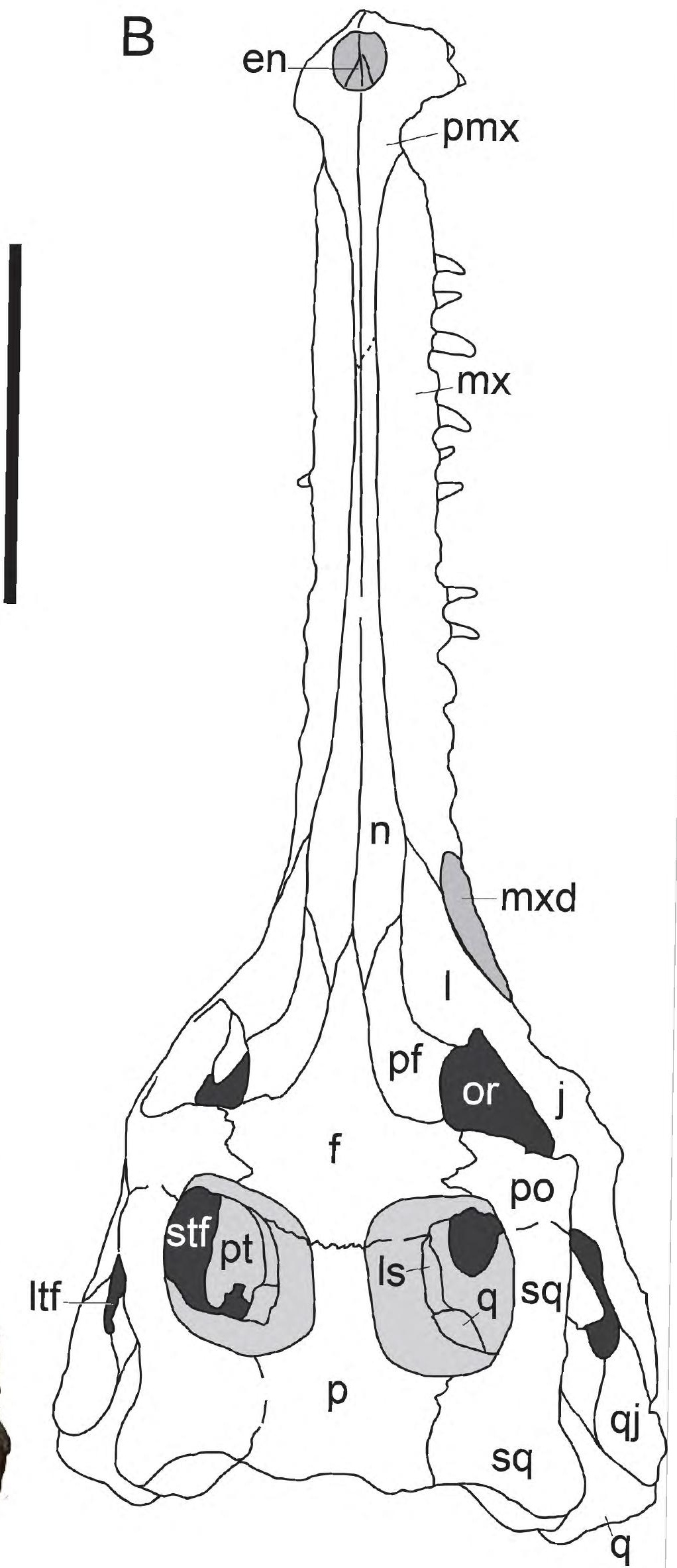


A

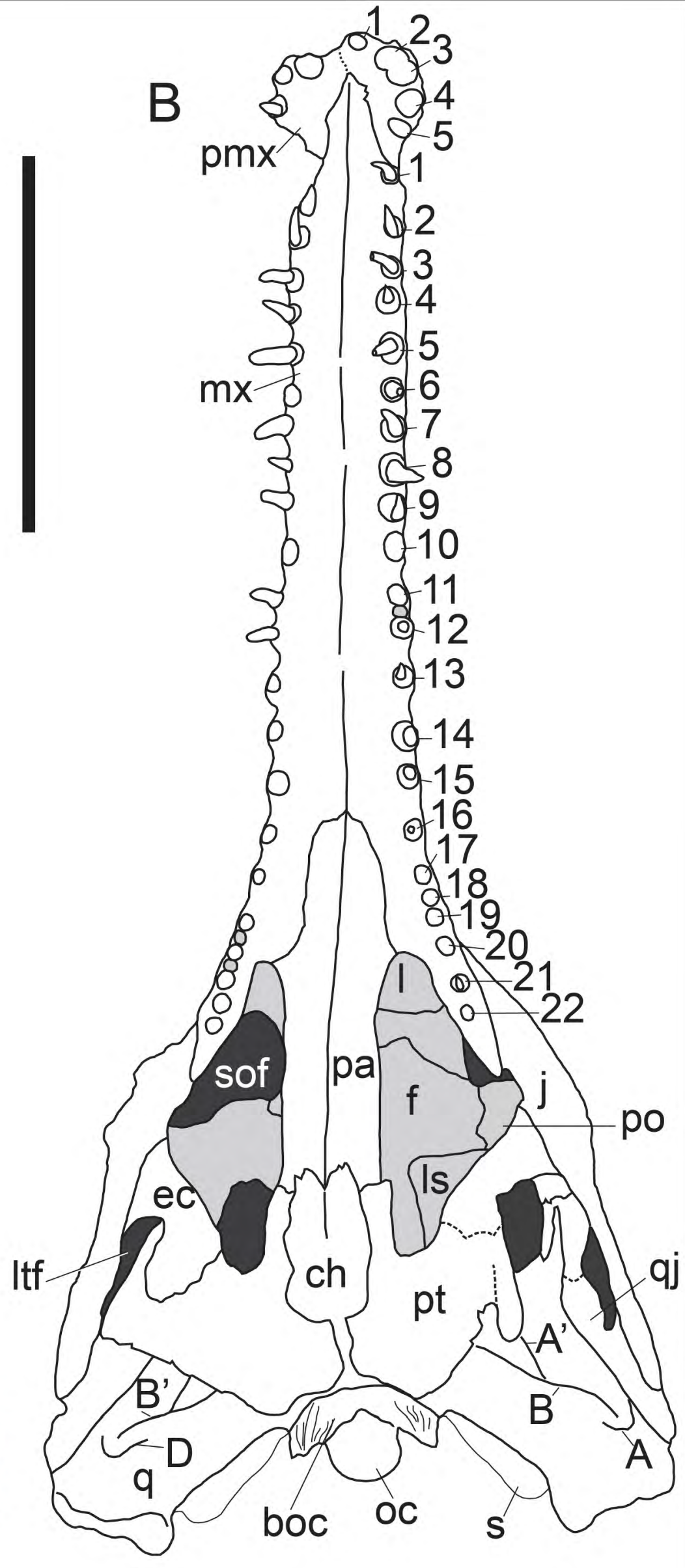




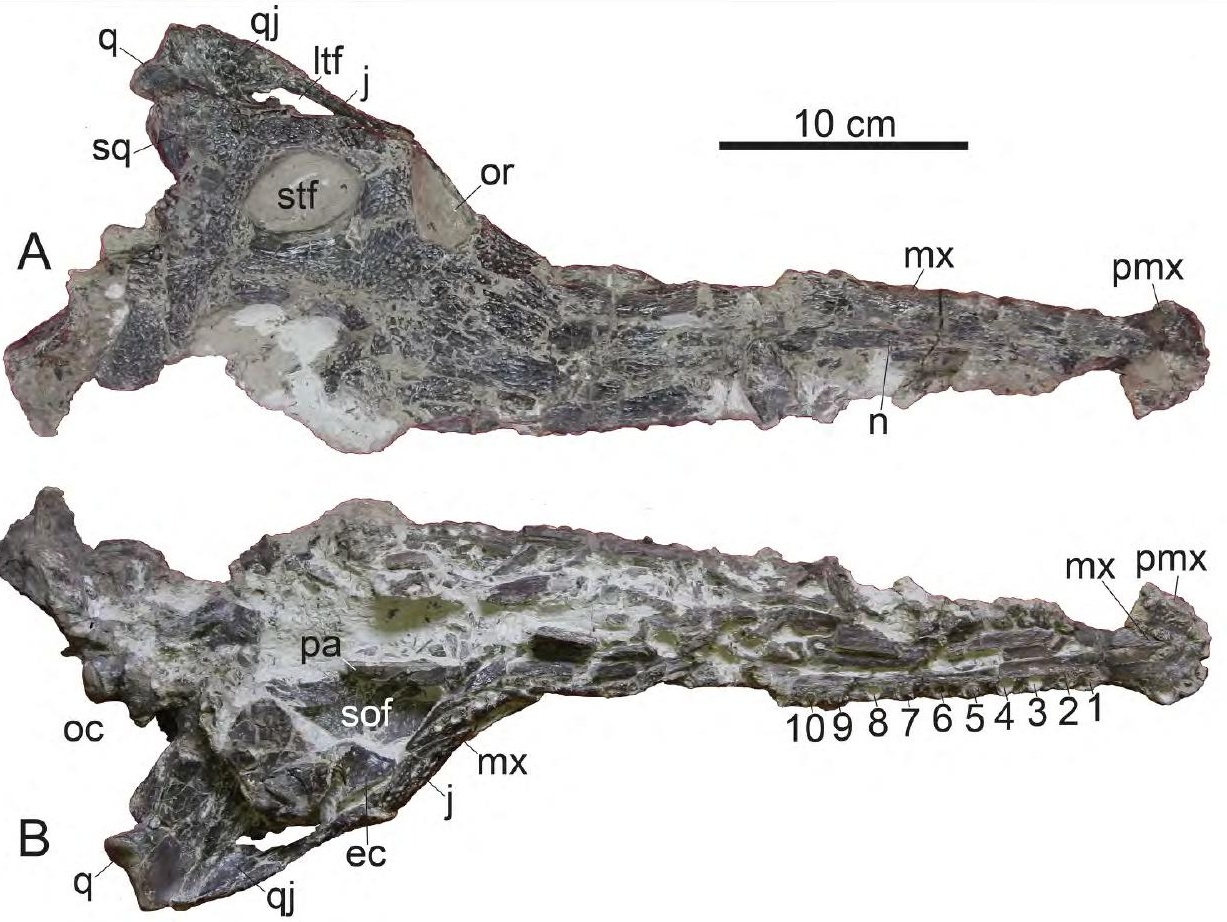




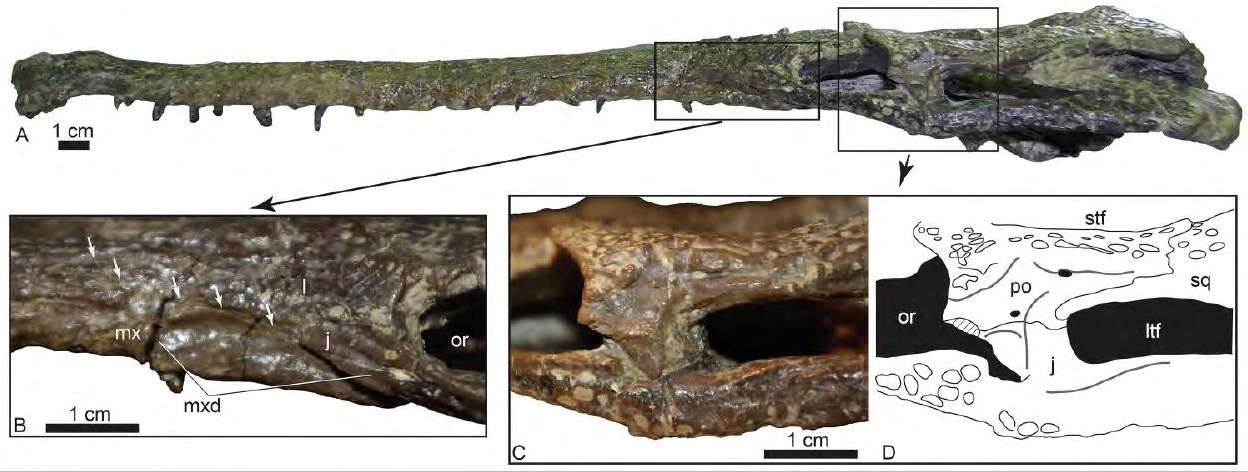




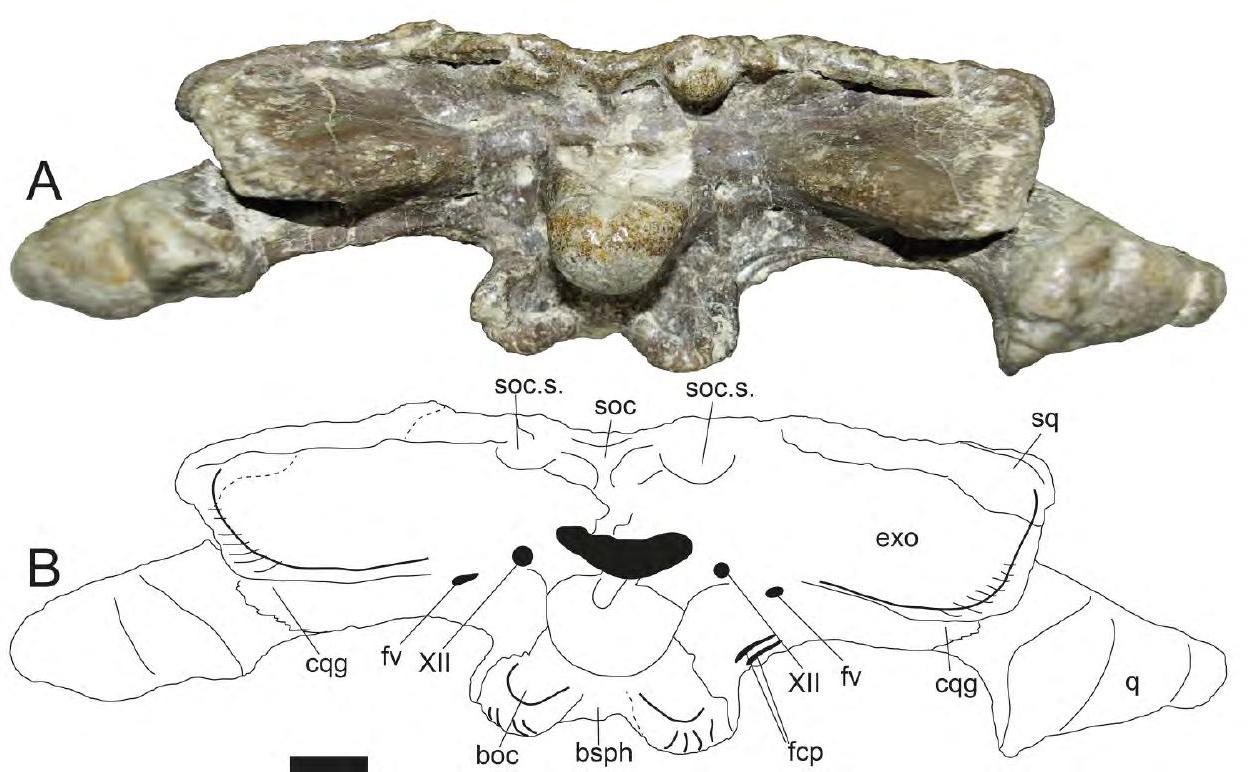


A

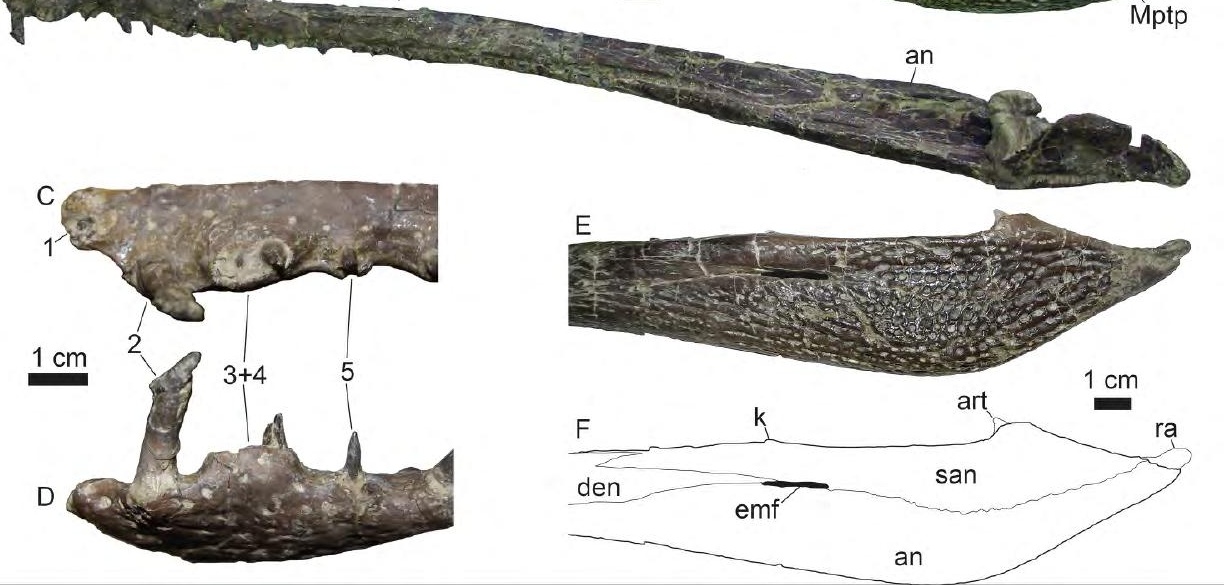

\section{4}

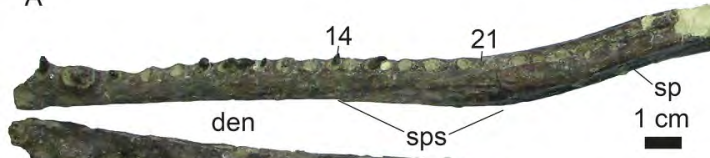

\section{xisc}



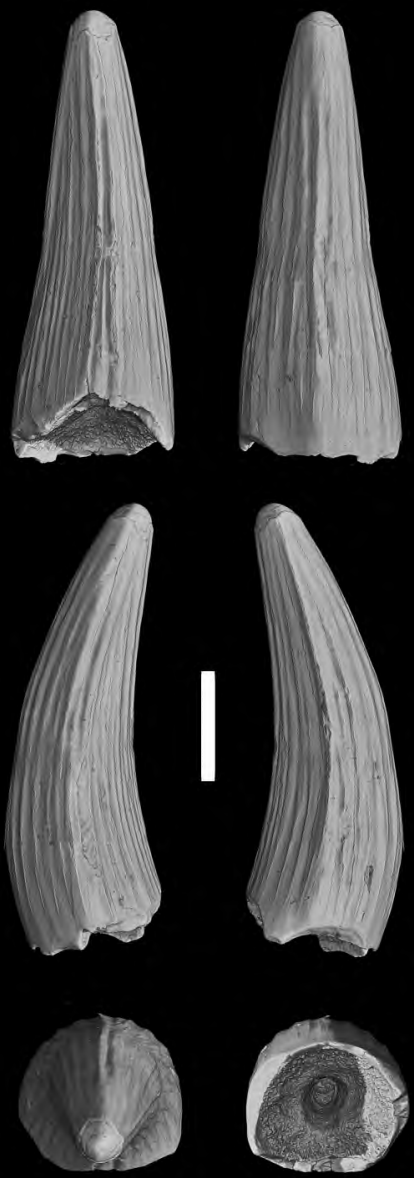


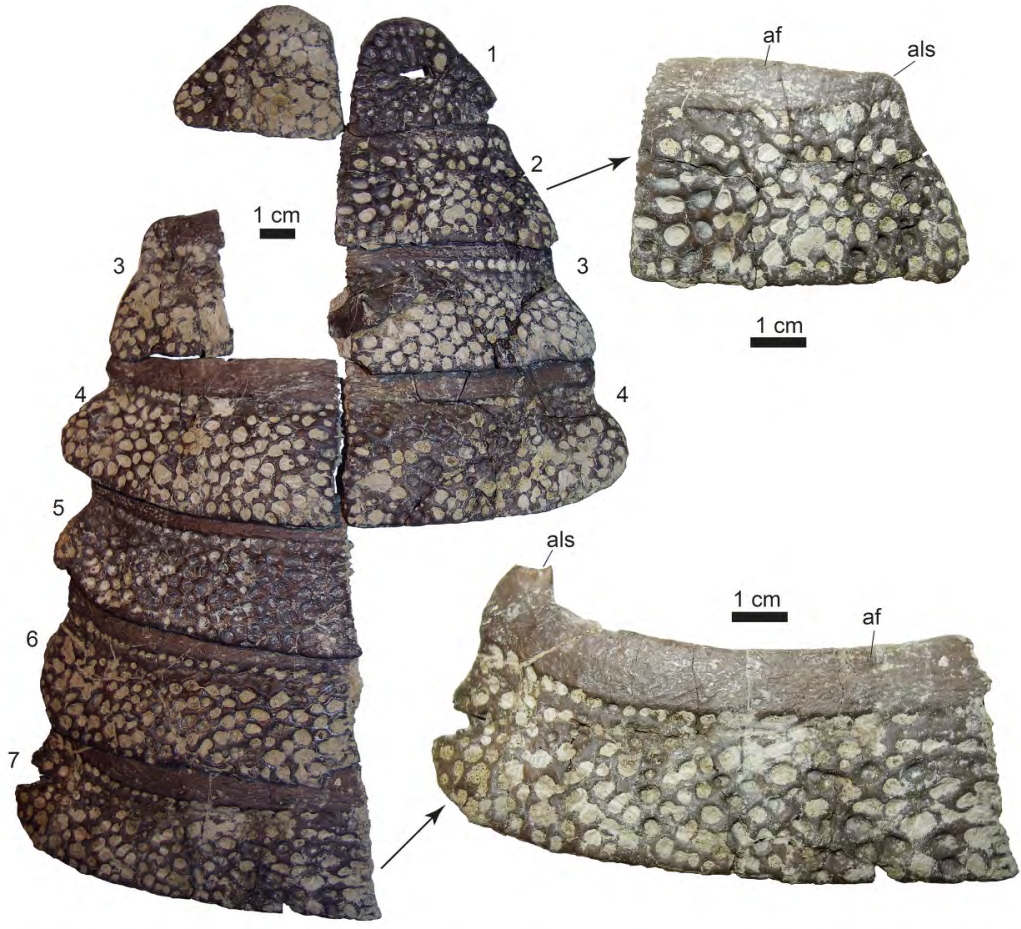


Ziphosuchia

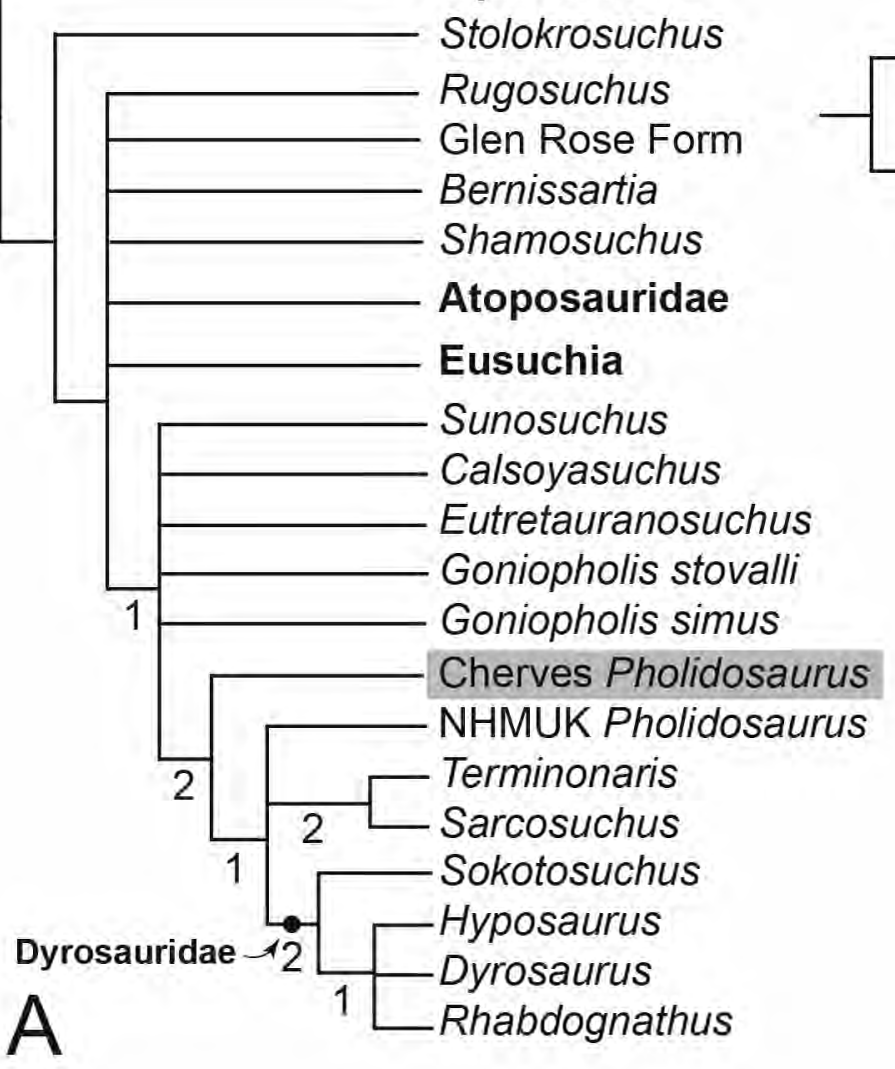

Ziphosuchia

Stolokrosuchus

Atoposauridae

Rugosuchus

Shamosuchus

Glen Rose Form

Bernissartia

Goniopholis simus

Eutretauranosuchus

Goniopholis stovalli

Sunosuchus

Calsoyasuchus
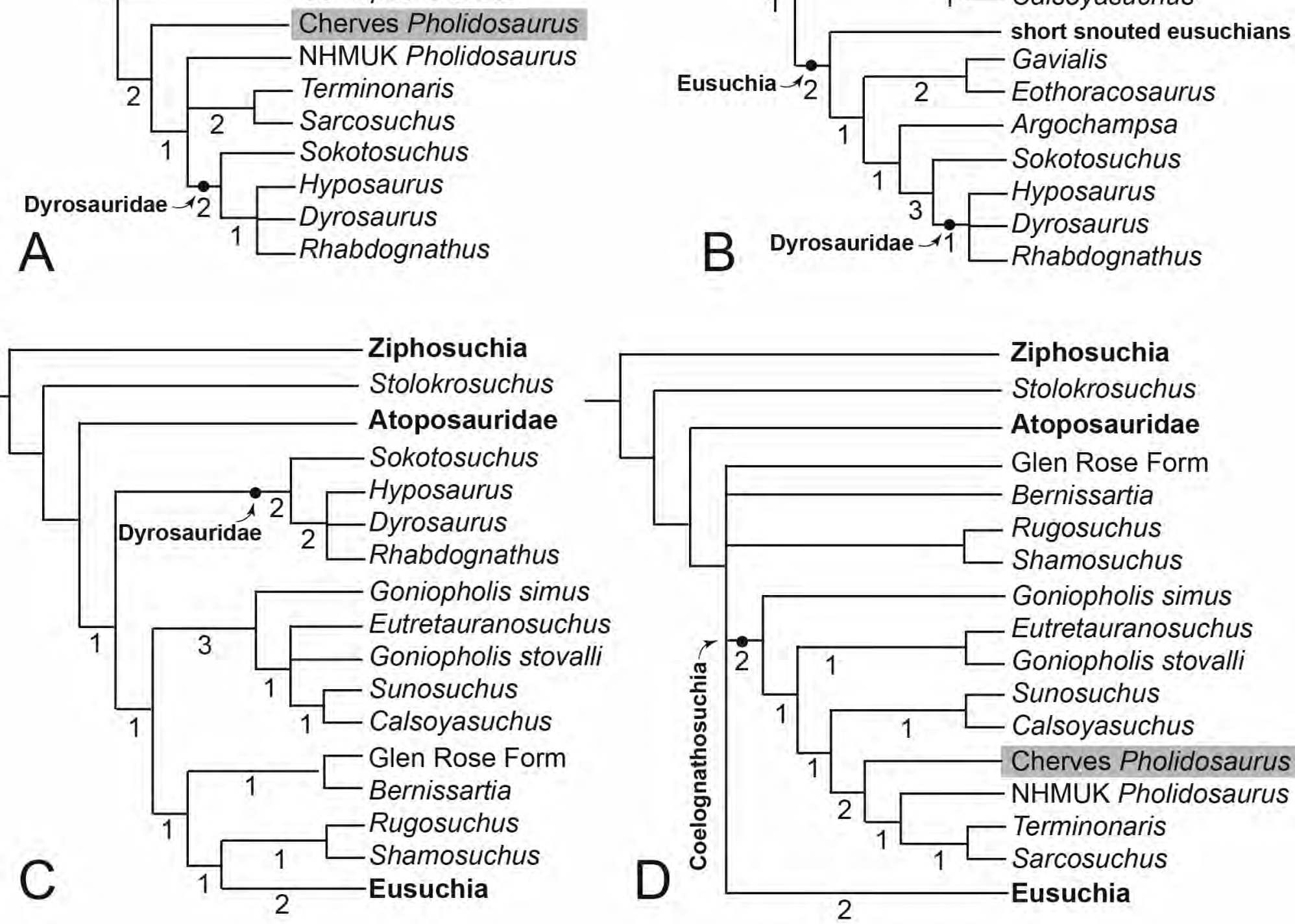
Table 1. Dimensions (in cm) of the skull and and mandible of Pholidosaurus purbeckiensis (CHV03.100) from the Berriasian of Cherves-de-Cognac, France

\section{Skull}

Length of skull from pmx tip to posterior edge of cranial table 36.9

Maximal width of skull, across quadratojugals 15.4

Length of snout 25.7

Length of post-snout region, from anterior border of orbit to posterior edge of cranial table 11.2

Maximal width of snout (at largest maxillary tooth) 3.8

Maximal length of naris 1.6

Maximal width of naris 1.4

Maximal length of orbit 3

Maximal width of orbit about 3

Interorbital width 4.8

Length of cranial table, through center of supratemporal fenestrae 8.7 (left)

Width of cranial table, across centers of supratemporal fenestrae 11.1

Maximal length of supratemporal fenestra 4.5 (left)

Maximal width of supratemporal fenestra 3.8 (left)

Anteroposterior thickness of postorbital bar 1.4 (left)

Interfenestral (supratemporal) width 1.5 (ornamented surface)

Length of ventral border of infratemporal fenestra 4.4 (left)

Length of long axis of suborbital fenestra 8 (right); 7.9 (left)

Length of short axis of suborbital fenestra 3 (right); 3.6 (left)

Interfenestral width of palatines at mid length 2.6

Width of choanae 2

Max. Width across pterygoid flanges 10.5

\section{Mandible}

Length of symphysis 17.4 (left), 17.5 (right)

Total length $=$ symphysis $+28.8($ left $)$ 
Height of symphysis near posterior end 1.5 (left) 